\title{
La problemática de la ganancia en la economía y su relación con la contabilidad empresarial
}

\author{
The problem of the profit in economic theory and business accounting
}

Luis Kato Maldonado*

\section{Resumen}

El objetivo de este artículo es establecer la relación entre la teoría de la contabilidad y las escuelas económicas predominantes actualmente. En particular entre la teoría neoclásica y la teoría marxista. En el trabajo se hace una revisión de los conceptos y categorías que definen la contabilidad como disciplina explicando, su relación con la economía. Se analiza la forma en que la teoría neoclásica relaciona las categorías contables a su marco teórico. Asimismo se explica el concepto del ciclo de capital en la teoría marxista y se desarrolla su marco contable se expone que éste sustenta una contabilidad científica en la medida en que describe el proceso real de producción y por ende permite determinar el comportamiento práctico de la ganancia capitalista. Se concluye que el estudio del ciclo de capital soluciona los siguientes problemas de contabilidad: Qué deben incluir los capitalistas en sus costos de producción y cómo deben ser medidos, cómo deben los capitalistas reconocer sus ingresos, cómo pueden depreciar los capitalistas el capital constante fijo, cómo deben los capitalistas contabilizar los cambios en los precios, cómo entender la obtención de ganancias como un proceso de explotación de la fuerza de trabajo.

Palabras clave:

- Neoclásicos

- Marxistas

- Consumo, Ahorro, Producción

\begin{abstract}
The aim of this paper is to establish the relationship between accounting theory and currently prevailing economic schools. In particular between neoclassical theory and Marxist theory. This article is a review of the concepts and categories that define accounting as discipline and its relationship to the economy. In this paper we discuss the way that neoclassical theory relates the accounting categories to their theoretical framework. It also explains the concept of capital cycle in Marxist theory and how this theory set forth her accounting framework, it stated that this theory have validity scientific given that it describes the actual production process and thus it enables determine the practical behavior of the profit capitalist. We conclude that capital cycle study allow understand the following accounting issues: what must include the capitalists in their production costs and how they must measure, how should the capitalists recognize her cost and how they can depreciate the fixed constant capital, and finally how the capitalists must analyze the changes her prices as a process of exploitation of labor power.
\end{abstract}

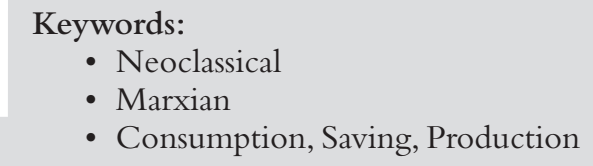
tabilidad y las escuelas económicas predominantes actualmente. En particular entre la teoría neoclásica y la teoría marxista. La vinculación entre la concepción del funcionamiento de la economía y la contabilidad se estima como una relación clara. No obstante dicha vinculación está lejos de ser evidente

* Departamento de Economía, Universidad Autónoma Metropolitana-Azcapotzalco.jarumi@prodigy.net.mx . . - . 
Economía Informa núm. 383 noviembre - diciembre • 2013 | " " "

y determinada biunívocamente. En tal sentido, y parafraseando a Keynes, detrás de toda política acción o decisión de empresas, gobierno y organizaciones sociales hay siempre un concepción económica concebida tiempo atrás que dan contenido a las medidas tomadas. ${ }^{1}$ Dichas concepciones no necesariamente son válidas científicamente y por ende, el asumirlas sin considerar su marco ideológico trae como consecuencia efectos sociales no esperados. La manera como se presentan las cosas no es la manera como son; y si las cosas fueran como se presentan la ciencia entera sobraría. ${ }^{2}$ Lo anterior es válido de manera más evidente sobre todo a raíz de la gran crisis que actualmente vivimos y en la cual, los criterios de rentabilidad de las empresas industriales, inmobiliarias y del sector bancario fueron evidenciados como erróneos traduciéndose lo anterior en la quiebra de prácticamente todo el sistema financiero internacional y en niveles de desempleo similares a los observados en la gran depresión de 1929. En tal sentido, vale la pena considerar como las concepciones económicas han influido en los conceptos y principios contables que actualmente nos rigen y que a la luz de lo comentado anteriormente están siendo cuestionados profundamente. El presente artículo se organiza de la siguiente manera: La primera parte hace una breve revisión de los conceptos y categorías que definen la contabilidad como disciplina explicando, a partir de las definiciones más aceptadas sobre el objeto de estudio de esta disciplina su relación con la economía. A partir de lo anterior, se desarrolla cuál es la escuela económica que más ha influido en la determinación del objeto de estudio de la economía. Es decir, se analiza la forma en que la teoría neoclásica relaciona las categorías contables a su marco teórico. En esta sección se ubican los supuestos teóricos neoclásicos sobre los cuales las definiciones contables tienen sus sustentos. En la segunda parte se examina y explica el concepto del ciclo de capital en la teoría marxista y se desarrolla su marco contable a partir de éste, se explica el carácter científico de esta contabilidad en la medida que describe el proceso real de producción y por ende permite determinar el comportamiento efectivo de la ganancia capitalista. En el hecho de que existe una de crisis de la contabilidad, la teoría marxista desarrolla un análisis que posibilita encontrar las interrelaciones existentes entre procesos técnicos y la generación de plusvalor, estableciendo la relación que existe entre las esferas de la producción y la circulación. La naturaleza especifica de la duración del proceso de trabajo, la composición del capital y su rotación se convierten en temáticas que deben ser discutidas

\footnotetext{
${ }^{1}$ Tras cualquier acción de un político se puede encontrar algo dicho por un intelectual quince años atrás (John Maynard Keynes).

${ }^{2}$ Karl Marx.
} 
para comprender la formación de precios. Asimismo, se considera la naturaleza temporal de la organización social de la producción permitiendo con ello centrar la explicación de la rotación del capital a partir de los procesos de competencia capitalista que se van estableciendo históricamente lo cual implica que cada productor privado e independiente tendrá que evaluar las necesidades sociales, las condiciones de competencia con otros productores; determinar el comportamiento de los mercados de materias primas y auxiliares, así como los patrones de evolución tecnológica que sigue el proceso productivo. Es decir, el análisis del ciclo de capital industrial permite dilucidar cómo la producción de mercancías es producto del trabajo socialmente necesario y establece, a partir de lo anterior, los fundamentos de una contabilidad científica en la medida en que solucionan los siguientes problemas:

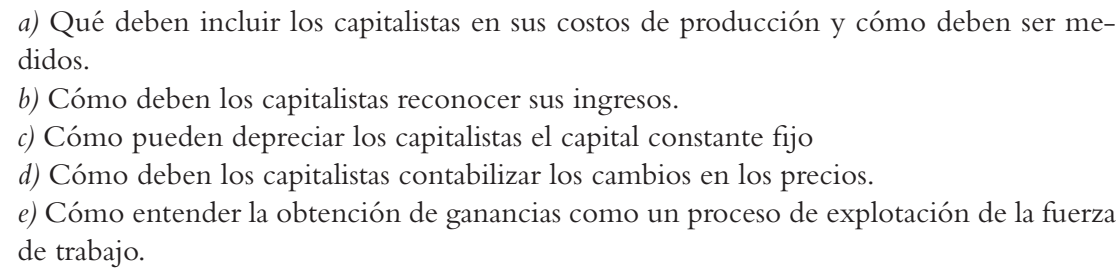

\section{La contabilidad y la teoría neoclásica}

Existen múltiples definiciones sobre que es la contabilidad las cuales las podemos clasificar de acuerdo al énfasis que subrayan respecto a su campo de estudio a saber: la contabilidad orientada al estudio del cálculo del control productivo-comercial ${ }^{3}$ de las empresas, al estudio de la capacidad patrimonial de las empresas en el tiempo, ${ }^{4}$ al estudio del comportamiento económico de las empresas el cual comprende a su vez: el análisis de la capacidad hacendaria

\footnotetext{
${ }^{3}$ Doctrina o ciencia, rama de la matemáticas aplicadas a la administración, que mediante anotaciones veraces, completas, coordinadas, sistematizadas y resumibles, permite definir y regular una actuación económica o administrativa. Jorge Tua Pereda, 1998, p. 6.

${ }^{4}$ La Contabilidad es la ciencia que deduce de la teoría económica y jurídica el conjunto de principios que deben regular el registro ordenado de las operaciones económicas ejecutadas en un patrimonio hacendal, a fin de conocer, orientar y criticar una actuación económico-administrativa. Citado por Jorge Tua Pereda, 1998, p. 9. "El objeto de la Contabilidad es el patrimonio hacendal, considerado en sus aspectos estático y dinámico, cualitativo y cuantitativo... y su fin es el gobierno oportuno, prudente, conveniente, de tal patrimonio en las empresas y en los entes de cualquier naturaleza, sea en situación de constitución, sea en situación de gestión, sea en situación de transformación, cesión, fusión o liquidación”. Citado por Jorge Tua Pereda, 1998, p. 13.
} 
Economía Informa núm. 383 noviembre - diciembre • 2013 | " " "

de las empresas ${ }^{5}$ y el proveer información a los inversionistas sobre el comportamiento económico de las compañías. ${ }^{6}$

En apariencia los diversos énfasis puestos sobre el campo de estudio de la contabilidad parecerían no tener contradicciones de fondo entre sí, sin embargo, las diferencias son sustanciales en la medida en que los dos primeros objetos de estudio enfatizan el control y sistematización del proceso de producción y del valor de los acervos. Los restantes subrayan el establecimiento de normas contables, válidas para cualquier actividad productiva, orientadas a la evaluación económica de las empresas.

Considerando las definiciones básicas del objeto de estudio de la contabilidad a saber: el estudio del cálculo del control productivo-comercial y de la capacidad patrimonial de las empresas en el tiempo, podemos afirmar que esta disciplina dio las bases para la determinación de procesos de registro veraces que permitieron la sistematización temporal de las principales actividades de intercambio y la actuación económica administrativa de las empresas. Al mismo tiempo, los registros contables acreditaron que la utilización de la información derivada de éstos, léase activos, fueran prueba de garantía para hacer frente a las obligaciones actuales y futuras de las distintas empresas las cuales se expresan en pasivos.

La contabilidad como disciplina de haber continuado con estos objetivos de medición debió de haberse obligado a desarrollar plenamente un marco axiomático que proporcionara bases metodológicas comunes para los sistemas contables de cualquier clase y en consecuencia generar una teoría general contable. Para lograr tal fin la contabilidad requería de una concepción general del movimiento del capital y una teoría objetiva del valor que explicara el origen y fuente de la ganancia. Al no realizarlo la contabilidad como disciplina

5 “La Contabilidad, desde el punto de vista teórico, estudia y enuncia las leyes del control económico en las haciendas de cualquier clase, y deduce las oportunas normas a seguir par que dicho control sea verdaderamente eficaz, convincente y completo; desde el punto de vista práctico, es la aplicación ordenada de estas normas a las distintas haciendas." Citado por Jorge Tua Pereda, 1998, p. 12.

6 "Es una actividad de servicio, cuya función es promover información cuantitativa, principalmente de naturaleza financiera, acerca de las entidades económicas, con el propósito de que sea útil para la toma de decisiones económicas, al hacer elecciones racionales entre recursos de acción alternativas". "El propósito de los estados financieros es la expresión, en términos financieros, de la utilización de los recursos económicos de la empresa y los cambios resultantes en ellos y en la posición en los mismos de los intereses de acreedores e inversores". "La Contabilidad es la ciencia de las cuentas, que representa los movimientos de los valores de cambio clasificados en sus funciones principales y clasificaciones de todos los valores materiales o jurídicos, servicios, desembolsos y otros que influyen en las situaciones de los patrimonios privados o públicos. Estos sistemas de Contabilidad potenciales no tratan con los aspectos de renta y riqueza en sentido ordinario, por lo que no pueden considerarse como Contabilidad económica". Citado por Jorge Tua Pereda, 1998, p. 24. 
se convirtió en un conjunto integral de disposiciones conceptuales formales y metodológicas que explican el sentido de las variaciones del patrimonio de las empresas y en donde la clasificación de sus cuentas es siempre válida independientemente del proceso específico de producción o servicios que pretende medir, siendo sus principales identidades las siguientes.

\section{Identidades contables básicas}
Relación entre el estado de resultados Relaciones entre el Balance Estado de y el balance
Activo $=$ Pasivo + Patrimonio, $\quad$ Definiendo:
$\mathrm{AC}=$ Activo Circulante
Activos $=$ Pasivos $+[$ Capital Aporta- do + Utilidades Retenidas]
ANC $=$ Activo no Circulante
$\mathrm{PC}=$ Pasivo Circulante
PNC $=$ Pasivo no Circulante
$\Delta$ Activos $=\Delta$ Pasivos $+\Delta$ Capital $\quad$ PAT $=$ Patrimonio
Aportado $+\Delta$ Utilidades Retenidas
El cambio de utilidades se explica por
el resultado del ejercicio menos los dividendos declarados en el período.
$\Delta=$ cambio en un ítem en un período de tiempo
Tenemos:
$\mathrm{AC}+\mathrm{ANC}=\mathrm{PC}+\mathrm{PNC}+\mathrm{PAT}$

$\Delta$ Activos $=\Delta$ Pasivos $+\Delta$ Capital Aportado + Resultado del Ejercicio - Dividendos

Capital de trabajo $(\mathrm{t})=$ Activos Circulante $(\mathrm{t})$ - Pasivos Circulantes $(\mathrm{t})$
Esta identidad debe cumplirse tanto al comienzo como al final de un período, por lo tanto:

$\Delta \mathrm{AC}+\Delta \mathrm{ANC}=\Delta \mathrm{PC}+\Delta \mathrm{PNC}+\Delta$

PAT

$\Delta$ Capital de Trabajo $=\Delta$ PNC $+\Delta$ $\mathrm{PAT}-\triangle \mathrm{ANC}$

${ }^{7}$ Suponiendo que la empresa no hay capitalizado utilidades retenidas en el período. 
Economía Informa núm. 383 noviembre - diciembre • 2013 | - " " "

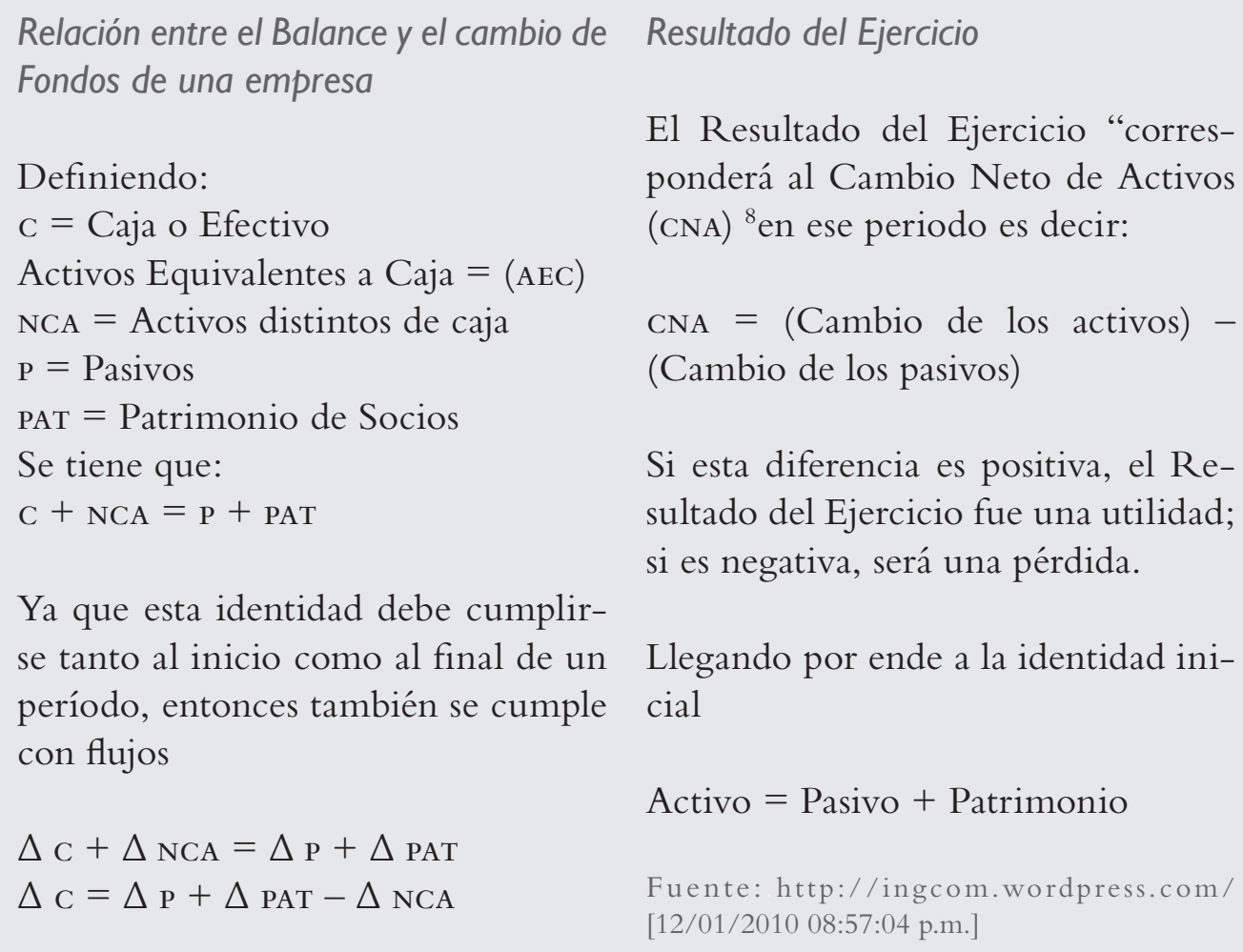

Definiendo:

$\mathrm{C}=$ Caja o Efectivo

Activos Equivalentes a Caja $=($ AEC $)$

NCA $=$ Activos distintos de caja

$\mathrm{P}=$ Pasivos

PAT $=$ Patrimonio de Socios

El Resultado del Ejercicio “corresponderá al Cambio Neto de Activos (CNA) ${ }^{8}$ en ese periodo es decir:

Se tiene que:

$\mathrm{C}+\mathrm{NCA}=\mathrm{P}+\mathrm{PAT}$

CNA $=$ (Cambio de los activos) (Cambio de los pasivos)

Si esta diferencia es positiva, el Resultado del Ejercicio fue una utilidad; si es negativa, será una pérdida.

Ya que esta identidad debe cumplirse tanto al inicio como al final de un período, entonces también se cumple con flujos

$\Delta \mathrm{C}+\Delta \mathrm{NCA}=\Delta \mathrm{P}+\Delta \mathrm{PAT}$

$\Delta \mathrm{C}=\Delta \mathrm{P}+\Delta \mathrm{PAT}-\Delta \mathrm{NCA}$

Llegando por ende a la identidad inicial

Activo $=$ Pasivo + Patrimonio

Fuente: http://ingcom.wordpress.com/ [12/01/2010 08:57:04 p.m.]

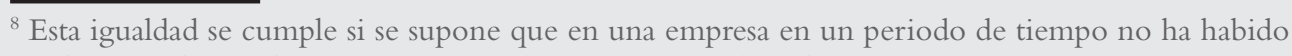
cambios en el capital aportado por sus dueños ni retiro de utilidades.

La Contabilidad actualmente se ocupa de la medición en sentido amplio y abstracto, el centro de interés son precisamente las cuentas, no el proceso económico real propiamente dicho que dan contenido a las cuentas de las empresas y al cambio del valor en el patrimonio de las mismas. La posibilidad real de que el simple análisis de las cuentas pueda cumplir con estos objetivos se sustenta en una visión sobre la realidad económica de carácter abstracto en donde la materialidad de las relaciones económicas se describa a partir de precios relativos los cuales identifican las acciones racionales de los agentes económicos. Esta realidad sólo existe en el mundo neoclásico de competencia perfecta.

El análisis neoclásico de la producción, y de los costos que se derivan de ésta, es desarrollado a través de la definición y formalización de la denominada función de producción. 
La función de producción es la exposición de la relación funcional entre los insumos y la producción. Muestra la producción máxima que se puede obtener de determinados insumos. Es una relación tecnológica y resume la tecnología más avanzada para obtener la producción. ${ }^{9}$

En la función de producción el hecho que los procesos estén verticalmente integrados, o que operen en paralelo unos respecto a otros, se ignora completamente, los distintos tipos de máquinas utilizados y el trabajo utilizado, se relaciona directamente con el producto final. En consecuencia, el volumen de producción puede considerarse como una función del volumen de las materias primas, maquinaria y trabajo. La función de producción supone que se es capaz de presentar la sistematización de la producción a partir de la desagregación de las diversas materias primas, medios de producción y trabajo. Así pues sea $Y$ el volumen obtenido de producción, $K 1, K 2, \ldots, K n$ como el tiempo de funcionamiento de las máquinas 1 a $n$; $L$ la cantidad de trabajo gastada, $M$ el volumen de materias primas utilizadas. A cada valor de los insumos le corresponde distintos valores del producto desde cero hasta el valor máximo. De estos valores, la función de producción recoge únicamente la relación entre $K$, $L, M$ y el valor máximo $Y$ denominado frontera productiva. En consecuencia la función de producción debería escribirse correctamente como:

$$
\max Y=F(K ; L ; M)
$$

Así, pues, la función de producción no puede considerarse como una simple descripción de una relación técnica; debe considerarse como un concepto económico construido sobre el supuesto de que se ha presentado alguna consideración al problema de la eficiencia de gestión. A partir de este supuesto se puede establecer la relación entre factores y producto en la frontera estipulada por la función de producción.

Determinado la combinación de uso de insumos que es máxima, se supone que los procesos de producción son normalizados de forma tal que una unidad de estos procesos utiliza una máquina de un tipo durante una hora y una máquina de otro tipo durante el mismo periodo de tiempo teniendo una relación de proporciones directas. Cuando la intensidad de operación se aumenta, se supone que la relación por la cual las cantidades de factores y producto aumentan en proporción directa, no sólo se mantiene cuando la intensidad de operación aumenta en múltiplos que son números naturales, tal que como dos o tres; sino que se mantendrá también para cualquier multipli-

\footnotetext{
${ }^{9}$ Madala G. S. y Millar (1991), p. 160.
} 
Economía Informa núm. 383 noviembre - diciembre • 2013 | " " "

cador que sea un número real positivo pudiendo ser $1 / 2$ o raíz cuadrada de dos siendo por tanto un supuesto poco realista. Una vez adoptado esta suposición es posible normalizar cada proceso no sólo para las máquinas, sino también en términos de las materias primas, del trabajo y de los productos. Determinándose los llamados coeficientes técnicos con base a cualquier bien que se elija como medida siempre que se relacione con el proceso en cuestión. Además, el hecho de que los procesos puedan llevarse a cabo a tasas que pueden tomar valores no sólo de cualquier número natural, sino de cualquier número fraccionario (divisibilidad del proceso), significa que la actividad productiva es continua. Cuando los procesos son divisibles, el efectuar un proceso determinado a $x$ unidades intervendrá un número de factores y producto igual a $x$ veces número en el proceso normalizado.

La expresión genérica de la función de producción se basa en la definición de insumos (homogéneos y/o heterogéneos), la transformación de éstos a través de su utilización por medio de máquinas define los que es la tecnología. La maquinaria en si misma se concibe independiente del proceso de producción en las cuales son empleadas; las máquinas son entonces disponibles para diferentes clases de procesos técnicos. La anterior concepción sobre la maquinaria se hace evidente cuando se analizan las funciones agregadas de producción donde diferentes combinaciones de factores homogéneos de capital y trabajo arrojan diversos niveles de productos; asimismo se puede utilizar un modelo multisectorial donde los procesos de cada sector son caracterizados por coeficientes técnicos que reflejan diferentes combinaciones de insumos tal que se puede reconfigurar la capacidad producción por medio de la relocalización de los insumos entre sectores..$^{10}$

La propuesta analítica desarrollada por la escuela marginalista reconoce la existencia de $n$ funciones de producción los cuales pueden ser representados en un

${ }^{10}$ Una forma de definir la función de producción consiste en establecer un vector de producción este es un vector $y=\left(\gamma_{1}, \chi^{2}, \ldots, y L\right) \in R^{L}$, donde $L$ es el conjunto de mercancías que puede producir una economía.

El análisis del comportamiento de la firma parte del supuesto de que el conjunto de todos los vectores de producción constituyen planes deseables de la firma lo cual es conocido como conjuntos de producción y se denotan como YC $R L$. Cualquier $y \in Y$ es posible, cualquier $\gamma \notin Y$ no es posible. El conjunto deseable es limitado en primer lugar por la restricción tecnológica o por restricciones legales.

La composición de vectores de producción es resultado de la utilización de insumos que dan un nivel determinado de producto. Es decir sea $Y=(\gamma 1, \ldots, y m) \geq 0$ como el nivel de producto de $M$ firmas y $X=(x 1, x 2, \ldots x L-M) \geq 0$ de insumos usados por $L-M$ firmas. Se dirá por tanto que un plan de producción (y) es técnicamente posible si el vector de producción bruta es menor o igual al conjunto de requerimientos de factores productivos (entradas). 
espacio de $n$ dimensiones de la siguiente manera $q=(q 1, q 2, \ldots, y n-x 1, x 2, \ldots, x n)$ $e R^{n}$ donde $q 1, \ldots, q n$ son los vectores de producto neto y $x 1, x 2, \ldots, x n$ son los vectores de insumos que permiten obtener el producto neto.

Las funciones de producción utilizadas para fines analíticos básicamente son dos: la función de producción de Leontieff y la función de producción Cobb-Douglas. La primera es empleada para el desarrollo del análisis multisectorial y la segunda para el análisis de la utilización de factores productivos que explican el comportamiento de la empresa y la tecnología que utiliza.

Para comprender el concepto de tecnología que sostiene la teoría neoclásica utilizaremos esta última función la cual tiene las siguientes características:

1. Presenta rendimientos constantes ante incrementos proporcionales de insumos. Así el empresario es capaz de maximizar su beneficio.

2. Es una función homogéneas de grado 1, con ello se garantiza que las productividades marginales de los factores de la producción no cambian ante incrementos de los insumos.

3. El producto total generado se agota a través del pago de factores.

Matemáticamente, esta función, a la cual denominaremos por f, está definida, para x e y no negativas, del siguiente modo:

$$
q=f(x, y)=A x^{a} y^{1-a}
$$

En donde $A$ y a son constantes positivas $(0<\mathrm{a}<1)$. $A$, establece el estado de la tecnología, $x$ e $y$ son los factores de producción — capital y trabajo-. El valor $f(x, y)$ significa la producción máxima que se puede obtener con la cantidad de capital $x$ y la cantidad de trabajo $y$.

El producto total obtenido en cada momento de la función nos define la situación de los conocimientos tecnológicos, en el momento considerado. Derivando parcialmente la función f con x e y se obtiene las productividades marginales de los insumos:

$$
\partial q / \partial x=a A x^{a-1} y^{1-a}
$$

(Productividad marginal de $\mathrm{x}$ )

$$
\partial q / \partial y=(1-a) A x^{a} y^{-a}
$$

(Productividad marginal de y) 
El uso de funciones de producción homogéneas de grado 1 garantiza que la suma de los pagos a los factores de producción es igual al producto. ${ }^{11}$

La teoría neoclásica determina un concepto básico el cual sintetiza todos los aspectos técnicos involucrados en un proceso productivo: la relación técnica de sustitución (RTS).

La RTS "es la pendiente de la tangente en un punto a la isocuanta y es la relación a la que debe sustituirse $x$ por $y$ (o $y$ por $x$ ) para mantener constante el nivel del producto."12 La RTs en un punto es igual a la razón entre la productividad marginal de $x$ y la productividad marginal de $\gamma$, es equivalente a:

$$
\operatorname{RTS}_{X Y}(q)=\frac{\partial F(q) / \partial x}{\partial F(q) / \partial y} \ldots(4)
$$

Considerando la función Cobb-Douglas tenemos que la relación técnica de sustitución se expresaría de la siguiente forma:

$$
\operatorname{RTSXY}(q)={ }^{\mathrm{a} A x 1^{\mathrm{a}-1} y^{1-\mathrm{a}}} / 1-\mathrm{a} A x^{\mathrm{a}} y^{-\mathrm{a}} \cdots(5)
$$

Con todos estos elementos es posible ubicar cuando el empresario maximiza beneficios en función de la utilización técnica.

Tomemos la función de producción Cobb-Douglas, y definamos la función de costos totales.

$$
\begin{gathered}
q=A x^{\mathrm{a}} y^{1-\mathrm{a}} \ldots \\
\mathrm{C}=\mathrm{r}_{1} \mathrm{x}+\mathrm{r}_{2} \mathrm{y} \ldots(7)
\end{gathered}
$$

Dónde: $C$ es el costo total, $r_{1}$ precio del factor $x$ $r_{2}$ precio del factor $\gamma$.

La función de beneficios quedaría definida como la diferencia entre ingresos menos costos es decir:

\footnotetext{
${ }^{11}$ Lo anterior puede ser demostrado aplicando el teorema de Euler. Este teorema establece que si $f(x, y)$ es homogénea de grado 1 entonces: $f(x, y)=x \frac{\partial f}{\partial x}(x, y)+y \frac{\partial f}{\partial y}(x, y)$

El caso de la función Cobb - Douglas, podemos comprobar lo anterior fácilmente ya que, por (3)

y (4), $x \frac{\partial f}{\partial x}(x, y)+y \frac{\partial f}{\partial y}(x, y)=x \mathrm{a} A x^{\mathrm{a}-1} y^{1-\mathrm{a}}+y(1-\mathrm{a}) A x^{\mathrm{a}} y^{-\mathrm{a}}=\mathrm{a} A x^{\mathrm{a}} y^{1-\mathrm{a}}+(1-\mathrm{a}) A x^{\mathrm{a}} y^{1-\mathrm{a}}=(\mathrm{a}+(1-\mathrm{a})) A x^{\mathrm{a}} y^{1-\mathrm{a}}=$ $A x^{\mathrm{a}} y^{1-\mathrm{a}}=f(x, y)$

${ }^{12}$ Henderson J. H., y Quandt (1981), p. 66.
} 


$$
\mathrm{p}=\mathrm{PAx}^{\mathrm{a}} \mathrm{y}^{1-\mathrm{a}}-\mathrm{r}_{1} \mathrm{x}-\mathrm{r}_{2} \mathrm{y} \ldots(\mathbf{( 8 )}
$$

Donde, $P$ el precio del bien producido.

En esta ecuación se observa que $\mathbf{p}$ es una función de $x$ e $y$ maximizándose con respecto a la utilización de insumos. Esta función supone que el empresario tiene libertad para variar los niveles de costo y de producto y su último objetivo es la maximización del beneficio. Si $x, y$ dan lugar al beneficio máximo entonces se cumple que:

$$
\begin{aligned}
& \text { Pa Ax }{ }^{a-1} \mathrm{y}^{1-\mathrm{a}}-\mathrm{r} 1=0, \ldots(9) \\
& \mathrm{P}(1-\mathrm{a}) \mathrm{Ax}^{\mathrm{a}} \mathrm{y}^{-\mathrm{a}}-\mathrm{r} 2 .=0 \ldots(10) \\
& \text { Por lo tanto: } \\
& \text { Pa Ax }{ }^{a-1} y^{1-a}=\text { r1 (11) } \\
& \mathrm{P}(1-\mathrm{a}) A x^{\mathrm{a}} \mathrm{y}^{-\mathrm{a}}=\mathrm{r} 2 \text {. (12) } \\
& \text { de lo que se deduce: } \\
& \begin{array}{c}
\mathrm{a} A x^{\mathrm{a}-1} y^{1-\mathrm{a}} / 1-\mathrm{a} A x^{\mathrm{a}} y^{-\mathrm{a}}=\mathrm{r} 1 / \mathrm{r} 2 \ldots \ldots . . \\
\mathrm{r} 1 / \mathrm{r} 2=a y /(1-a) x \cdots \cdots .(14)
\end{array}
\end{aligned}
$$

Como puede observarse la expresión indica que la razón de las productividades marginales de $x, y$ debe ser igual a la razón de sus precios.

De esta forma la maximización del beneficio se realiza condicionada a las restricciones técnicas de la función de producción.

Éstas a su vez satisfacen las siguientes relaciones:

1. El beneficio decrece a medida que se aumenta algún factor productivo por separado.

2. El beneficio decrece a medida que aumenta la utilización de ambos insumos conjuntamente.

3. Como el precio es mayor que cero se garantiza que las productividades marginales de ambos insumos son decrecientes.

4. El costo marginal es creciente en el largo plazo, los beneficios se maximizan igualando

el costo marginal al precio. 
Economía Informa núm. 383 noviembre - diciembre • 2013 | " " "

Lo expuesto hasta ahora permite determinar los costos y los beneficios de las diversas industrias en una fecha específica.

La secuencia temporal de la producción sin embargo tiene que ser considerada a fin de establecer los planes de producción de largo plazo. Durante el transcurso de un plan de inversión la utilización de insumos (decisiones tecnológicas) se realizan en el espacio de tiempo que transcurre entre dos fechas por ende las compras de insumos se realiza en la primera fecha. Asimismo la venta de productos se realiza en el siguiente periodo.

Lo antes expuesto se puede representar a través de la definición de una función de producción implícita:

$$
F\left(q_{12}, \ldots, q_{s L+1} ; x_{11}, \ldots \ldots . x_{n L}\right) \ldots \ldots(15
$$

"Donde $q_{j t}(j=1, \ldots . . s)(t=2, \ldots \ldots L+1)$ es la cantidad del $j$ - ésimo producto obtenido en el periodo $t$ - 1 y vendido $t$-ésima fecha del mercado; $x i t(i=1, \ldots, n)$ $(t=1, \ldots . L)$ es la cantidad del insumo $i$-ésimo comprado en la $t$-esima fecha del mercado y aplicado en el proceso de producción en el periodo $t$. El periodo máximo del plan está determinado por el tiempo $L+1$. Todo producto que el empresario pueda vender en la fecha de mercado inicial es el resultado de decisiones de producción pasadas y sus niveles se registran en (9) como constantes y no como variables. En la $(L+1)$-ésima fecha de mercado, el empresario planea vender los productos obtenidos durante el periodo $L$ no planea adquirir insumos, ya que no anticipa la producción en ningún periodo ulterior a $L$. La función de producción multiperiódica relaciona los niveles de insumos y productos de todos los períodos incluidos en el horizonte de planeación del empresario." ${ }^{\prime 3}$

La teoría neoclásica supone que el empresario se enfrenta también con un mercado de títulos perfectamente competitivo y es libre de prestar y pedir prestado dinero. La comparación de la rentabilidad relativa se asocia entonces a la tasa de interés o factor de descuento que induciría a un propietario de dinero a prestarlo.

En esta perspectiva la función de maximización ínter temporal se define de la siguiente forma:

$$
\mathrm{p}=\sum_{t=2}^{L+1} \sum_{j=1}^{S} p_{i j} q_{j t}(1+i)^{-1}-\sum_{t=2}^{L+1} \sum_{j=1}^{S}{ }_{i t} x_{i t}(1+i)^{-1}+\ldots .+\mathrm{I} F\left(q_{12} \ldots \ldots ; x_{n L}\right)(16)
$$

De esta función se deduce los principios de operación de cualquier empresa en el largo plazo a saber:

${ }^{13}$ Henderson J. H., y Quandt (1981), pp. 362-363. 


$$
\begin{gathered}
-d q_{j t} / d q_{k t}=\frac{d F / d q_{k t}}{d F / d q_{j t}}=\frac{p_{k t}(1+i)^{-1}}{p_{j t}(1+i)^{-1}}(17) \\
-d x_{i t} / d x_{h t}=\frac{d F / d x_{h t}}{d F / d x_{i t}}=\frac{r_{h t}(1+i)^{-1}}{r_{i t}(1+i)^{-1}}(18) \\
\mathrm{y} \\
P_{i t}(1+i)^{-1} d q_{i t} / d x_{i t}=-P_{i t}(1+i)^{-1} \frac{d F / d x_{i t}}{d F / d q_{i t}}=P_{i t}(1+i)^{-1} \frac{r_{i t}(1+i)^{-1}}{P_{i t}(1+i)^{-1}}=r_{i t}(1+i)^{-1}(19)
\end{gathered}
$$

La relación de transformación de productos (17) debe ser igual a las razones de los precios de los productos a su valor actual.

La relación técnica de sustitución es igual a la razón de precios de los insumos a su valor actual neto (18).

El valor descontado del producto marginal del insumo $X i$ aplicado al periodo $T$ con respecto a cada uno de los productos, obtenidos en cada uno de los periodos, debe ser igual al precios descontado de $X i$ en la $t$-ésima fecha del mercado (19).

El significado de estas reglas indica que la inversión se realizara hasta el punto en que se alcanza la rentabilidad media imperante en el mercado financiero expresada ésta en la tasa de descuento vigente para tipos de inversión similares.

${ }^{14}$ Los principios de operación de las empresas se deducen del siguiente razonamiento: para $t=1 \ldots L ; i=1, \ldots . n$ se obtiene:

$$
\begin{array}{ll}
d \mathrm{p} / d q_{j t}=p_{j t}(1+i)^{-1}+\mathrm{I} d F / d q_{j t}=0 & \rightarrow p_{j t}(1+i)^{-1}=\mid d F / d q_{i t} \\
d \mathrm{p} / d x_{i t}=-r i t(1+i)^{-1}+\mathrm{I} d F / d x_{i t}=0 & \rightarrow r_{i t}(1+i)^{-1}=\mid d F / d x_{i t} \\
d \mathrm{p} / d \mathrm{l}=F(q 12, \ldots, x n L)=0 &
\end{array}
$$

Dado que:

$$
\begin{aligned}
& -d q_{j t} / d q_{k t}=\frac{d F / d q_{k t}}{d F / d q_{j t}} \\
& -d q_{j t} / d x_{i t}=\frac{d F / d x_{i t}}{d F / d q_{j t}} \\
& -d x_{i t} / d x_{h t}=\frac{d F / d x_{h i}}{d F / d x_{i t}} \uparrow
\end{aligned}
$$

resulta las expresiones 11,12 y 13 para $t=2, \ldots ., L+1 ; j, k=1, \ldots \ldots n$. 
Economía Informa núm. 383 noviembre - diciembre • 2013 | " " "

Los flujos financieros obtenidos presuponen que los sistemas de producción están completamente codificados, que existe una tasa de interés que permite determinar el costo de oportunidad de capital, y que la tecnología está dada, lo cual significa que los productores, considerando la estructura de las tasas de interés, tienen la posibilidad de elegir la tecnología que permita maximizar los ingresos, o en su caso, minimizar los costos. En este sentido, el análisis temporal consiste en periodos de tiempos idénticos e independientes, en los que las personas encargadas de tomar decisiones asignan probabilidades subjetivas a los posibles beneficios de cada estrategia de inversión. Habiendo hecho esos cálculos para todas las alternativas, el empresario elige las que tienen el valor esperado más alto en cada periodo. Estos beneficios netos son descontados mediante la tasa de descuento subjetiva, lo que permite conocer el valor actual neto. La firma entonces escoge la estrategia que maximiza el valor actual neto del flujo futuro del beneficio neto en un horizonte temporal específico.

La articulación entre contabilidad y la teoría neoclásica queda entonces plenamente vinculada ya que ambas conciben la realidad económica como separada e independiente de lo que registra, y suponiendo su unicidad a través de un mercado plenamente competitivo. En consecuencia los estados financieros están enfocados a cumplir con las necesidad de los inversionistas no involucrados en la gestión directa de las empresas asumiendo que su principal requerimiento es el apoyo informativo adecuado a la toma de decisiones; por lo que no se trata ya de medir en abstracto unos hechos pasados, en búsqueda de un concepto único y autosuficiente de veracidad económica, sino de medir e informar con una finalidad concreta, la toma de decisiones, con lo que las necesidades del usuario constituyen el punto de partida para la determinación de las reglas contables y, en consecuencia, del contenido de los estados financieros. Es decir el usuario de la información contable necesita ésta para determinar sus decisiones óptimas a fin de establecer sus procesos de maximización. De acuerdo con esta orientación "los conceptos de renta o valor se definen en su entorno económico ideal y las técnicas o procedimientos alternativos se juzgan según su capacidad en relación con la medida de aquellos conceptos; al mismo tiempo, se asume, en general, que el sistema contable refleja adecuadamente la realidad económica y suministra unidireccionalmente información suficiente a los usuarios potenciales, de manera que no se plantean explícitamente la utilización de dicha información por parte de los usuarios. Al mismo tiempo trata de orientar el contenido de los estados financieros a las necesidades del usuario, asumiendo que su principal requerimiento es el apoyo informativo adecuado a la toma de decisiones. 
El enfoque 'activo y pasivo', derivado de la teoría económica neoclásica, fue desarrollado en los Estados Unidos en la década de 1960 por el Instituto Americano de Contadores Públicos Certificados (AICPA) y en la década de 1970 y 1980 por el FASB. La Junta de normas contabilidad de Reino Unido (ASB) ha adoptado este enfoque. La ASB se comprometió en su declaración de objetivos a lograr: "Principios de desarrollo para guiarla en establecer normas y proporcionar un marco dentro del cual otros pueden ejercer juicio para resolver problemas de contabilidad" (ASB, 1990). La ASB publicó capítulos del proyecto de una declaración de principios (sop) en 1991, 1992 y 1993; publicado un proyecto de exposición en 1995; emitió un borrador de exposición revisada a principios de 1999 y una versión final en diciembre de 1999.

En este sentido la contradicción fundamental de la contabilidad como disciplina es que por un lado es capaz de explicar aspectos de la realidad concreta tales como el patrimonio empresarial, el endeudamiento de las empresas y su capacidad de pago etc. y, al mismo tiempo los modelos existentes de contabilidad actualmente utilizados basan su cuantificación de modelos estandarizados de costos los cuales, por su propia naturaleza, no consideran las particularidades de los procesos productivos. Estos esquemas contables se fundamentan en la relación producto-proceso único que proponía la división de los costos fijos y variables para orientar las decisiones referentes a los productos y controlar los costos, pero nunca se investiga a fondo el origen los costos fijos ni la manera de repartirlos entre los productos de las unidades económicas.

Los sistemas de contabilidad gerencial no proporcionan información suficiente sobre la eficiencia de los procesos de producción, no pueden ser utilizados para reducir costos de producción pues una gran cantidad de desembolsos que no son calificados como costos de producción a saber: gastos de mantenimiento, mantenimiento de inventarios, reparaciones, depreciación, alteran la ganancia y por ende la obtención de plusvalía (Bryer 1999).

Las reacciones del mercado (reacciones anticipadas de precios) frente a las cifras contables se orientan a las evaluaciones del contenido de evaluación de dichas cifras y los procedimientos utilizados para producir dichas cifras. La necesidad de evaluación se formaliza en modelos para establecer precios al activo y capitalizar dividendos los cuales ocupan los siguientes esquemas contables:

1. Contabilidad ajustada a nivel de precios

2. Contabilidad de costos de remplazo

3. Contabilidad de valores de salida 
Economía Informa núm. 383 noviembre - diciembre • 2013 | " " "

4. Contabilidad del valor neto realizable

5. Contabilidad del valor presente

Cada uno de estos marcos contables presenta métodos alternativos de valuación de activos y determinación de la renta argumentando a su vez la superación de los defectos del sistema del costo histórico.

El método utilizado con frecuencia en este enfoque es el razonamiento analítico, recurriendo a los objetivos y postulados del entorno concluyendo con métodos específicos.

\section{Del marco teórico a la deformación de la realidad contable}

Los cambios en el objeto de estudio de la contabilidad se asocian no solamente a su vinculación con la teoría neoclásica sino también al concepto de gestión derivado a partir de la emisión de acciones y participación del capital financiero en la propiedad de las empresas capitalistas en la esfera de la producción y circulación. La gestión entonces se asocia a los inversionistas que participan en el control de la empresa. El control es en esencia la capacidad que se tiene de obtener ingresos a partir de considerar el dinero como un activo. Es decir, los derechos exigibles del dinero como capital expresados éstos como intereses, regalías, dividendos sobre acciones etc. En tal sentido, la gestión del dinero como capital se ejerce independientemente de cómo se determinan los activos y se establecen los pasivos de las empresas. La forma más común de controles de administración de capital es mediante el ejercicio de los derechos legales de propiedad de una sociedad anónima. Éstas son personas jurídicas con los derechos de propiedad que ejerce la administración, siendo éste el agente legalmente designado, en intereses de los inversores. Si la gestión de una empresa compra el capital social de otra sociedad el nuevo gestor evaluara el rendimiento de la adquisición como cualquier otro activo. Las inversiones pueden ser a corto plazo para obtener un rendimiento sobre el dinero excedente o temporal a largo plazo para obtener un rendimiento sobre el capital. A largo plazo las inversiones realizadas van desde la forma pasiva no participaciones de control, a través de empresas controladas de forma conjunta, a la gestión activa mediante participación mayoritaria.

La gestión del dinero como capital es la principal razón que tienen los directivos de las empresas que cotizan sus acciones, para intentar manipular las cuentas a través de la utilización de la contabilidad creativa. Dicha contabilidad consiste en aprovechar los vacíos de la normativa legal en cuanto a las 


\section{diferentes posibilidades de elección con el propósito de transformar la infor- mación contable que se presentan en los estados financieros de las empresas. \\ Las razones por las cuales se aplica la contabilidad creativa dan respuesta a la gestión del dinero como capital por parte de las empresas siendo esta gestión orientada a:}

1) Reflejar una tendencia estable en el crecimiento del beneficio, en lugar de mostrar unos beneficios volátiles con series de dramáticas subidas y bajadas.

2) Mantener o "incrementar" el precio de las acciones, tanto reduciendo los niveles aparentes de endeudamiento, y por tanto, haciendo que la empresa parezca expuesta a un riesgo menor, como creando la apariencia de una tendencia del beneficio creciente.

3) Utilizar la contabilidad creativa para beneficiarse de su información privilegiada.

\section{Algunas de estas transacciones son:}

a) Aumento o reducción de gastos: La normativa contable facilita un margen de maniobra en relación con la cuantificación en un determinado período de ciertos gastos o ingreso, como es el caso de las amortizaciones, de la depreciación o de la activación de ciertos gastos como por ejemplo los gastos de investigación y desarrollo.

b) Aumento o reducción de ingresos: En algunos casos se puede retrasar el reconocimiento de los ingresos, en virtud de principios tales como el de la prudencia o el de la correlación de los ingresos y gastos.

c) Aumento o reducción de activos: Los inventarios pueden valorarse según diversos métodos (FIFO, LIFO, Promedio Ponderado entre otros) con lo que la cantidad total puede diferir con los correspondientes efectos en los costos de ventas y el resultado. Estas modificaciones afectarán la relación entre los activos circulantes y los pasivos a corto plazo, influenciando directamente el índice de liquidez.

d) Aumento o reducción de las reversas: Las modificaciones en los ingresos o en los gastos, como se ha expresado anteriormente, afectan los beneficios o pérdidas y por tanto las reservas. De esta forma, se altera la proporción entre deuda y fondos propios con los correspondiente efectos en indicadores tales como el endeudamiento o apalancamiento financiero.

e) Aumento o reducción de deudas: En relación con ciertas partidas, la normativa contable permite la elección entre diversas posibilidades. Por ejemplo, en Europa para los fondos de pensiones existe la posibilidad de regularizar la deuda existente en un período que oscila, para la mayoría de las empresas entre 7 y 15 años. Por tanto, si una empresa le interesa aumentar su beneficio, por ejemplo, retrasará tanto como este permitido la regularización total de la deuda existente en concepto de planes de pensiones. Esta práctica también modifica el análisis de los índices financieros de endeudamiento, la independencia financiera o la liquidez.

f) Reclasificación de activos o pasivos: En otros casos puede existir un cierto margen a la hora de determinar si un concepto se incluye en un rubro o en otro. A modo de ejemplo, puede citarse el caso de ciertos elementos que pueden contabilizarse en el activo fijo o en el inventario. Esta posibilidad puede afectar a las relaciones entre los diversos rubros y por tanto, a los índices que permiten evaluar aspectos tales como la liquidez, rotación del inventario, capital de trabajo, entre otros.

g) Información incluida en la memoria, en el informe de gestión y en el informe de audi- 
Economía Informa núm. 383 noviembre - diciembre • 2013 | " " "

\begin{abstract}
toría: Existen secciones o cuerpos en las memorias y del informe de gestión en los que se puede incluir más o menos información. Ello puede derivar en cambios en la opinión que se desprenda de los mismos. En cuanto al informe de auditoría, en algunos casos pueden expresarse las salvedades $\mathrm{u}$ opiniones de forma que se busque una determinada interpretación de los mismos.

h) Presentación de la información: otra posibilidad para la contabilidad creativa la proporcionan los criterios utilizados para la presentación de la información, la cual de acuerdo al

"maquillaje" utilizado puede formar una opinión contraria a la realidad o de acuerdo a los intereses de la empresa.
\end{abstract}

\title{
Contabilidad y teoría marxista
}

En el tomo ir del capital Marx (Marx, Karl (1982)) desarrolla un análisis sobre los ciclos de capital y un método conceptual de la dinámica económica a través del proceso de producción capitalista. El ciclo del capital enfatiza la relación entre acervos y flujos. Esta articulación conceptual constituye una alternativa a la función de producción como método de análisis de la producción. Si bien el ciclo de capital es una representación general de los movimientos del capital en general es asimismo, la representación del movimiento de los capitales privados e independientes los cuales operan en diferentes momentos del ciclo e incluyen la producción y ventas de mercancías en diferentes tiempos. El ciclo del capital como acervo de valor enlaza la producción capitalista como resultado de un rezago en el tiempo, más bien que como factor productivo independiente, siendo esto compatible con la teoría del valor trabajo. Cambios en la inversión de capital por hora hombre trabajada, o por unidad de producto, son descompuestos en los circuitos de capital dentro de los cambios en el tiempo de rotación requerido por fase de producción derivados y las generaciones de las diversas inversiones de capital así como la división entre salarios y no componentes no saláriales. Esta circunstancia refleja las condiciones reales de competencia entre los diferentes capitales los cuales producen y consumen mercancías en función de las necesidades temporales de los patrones de demanda (Foley, 1997). Estas condiciones desde la perspectiva del proceso de valorización son las siguientes:

El proceso de producción en general se concibe desde el punto de vista técnico como la acción de la capacidad de trabajo que se despliega a través de la maquinaria y las herramientas sobre diferentes objetos materiales que serán transformados con el fin de obtener un producto cualitativamente diferente. En la relación social capitalista, estos objetos materiales se ordenan y pasan a lo largo de una secuencia de procesos de transformación racionalmente organizados y controlados; la secuencia analítica de estos procesos parciales describe el uso productivo de las materias primas y materias auxiliares, que son modi- 
ficadas por la acción de diferentes trabajos que utilizan diversas herramientas y maquinarias. El desarrollo de estos procesos parciales está acotado por un tiempo determinado, de lo contrario el proceso parcial sería ineficiente, y el objetivo del proceso productivo - la producción de mercancías - no se podría realizar en términos socialmente productivos. De esta forma, el fin fundamental de todo proceso de producción capitalista es la realización del trabajo en el menor tiempo posible, lo cual supone un uso racional y eficaz tanto de la maquinaria como de los medios de trabajo que serán utilizados para la transformación de las materias primas.

El ciclo del capital como proceso periódico es la rotación del capital, su duración se determina por el tiempo de producción y el tiempo de circulación del capital. Por consiguiente, mide el intervalo de un periodo cíclico de todo el valor del capital y el que lo sigue y por ende mide le número de repeticiones del proceso de valorización en consecuencia, la rotación de capital necesariamente implica observar la producción como un proceso dinámico.

La relación entre proceso de producción y rotación, considerando que el mercado está plenamente constituido, es la siguiente:

Cada capitalista expresamente, considera que el abastecimiento de los insumos, el uso de los recursos naturales, y la cantidad de trabajo incorporado en el momento $t$ se relacionan con procesos productivos integrados que determinan la viabilidad técnica del sistema de coordenadas que definen su proceso de producción. En función de ello, la tasa de productividad de la fuerza de trabajo puede ser determinada considerando que el obrero se ve sujeto a las leyes que enmarcan las condiciones de operación del sistema productivo, en el cual la productividad de éste aumenta conforme se incrementa la utilización de los elementos que lo componen, por esto, la norma de productividad de la fuerza de trabajo será una función de la cantidad de producto generado. [Aglieta, M. (1976), Coriat, B. (1976) Coriat, B. (1990) y Kanawaty, G. (1998)]. Lo antes explicado puede ser enunciado en una simple ley: a medida que una economía capitalista se desarrolla, y con ella las técnicas de producción, toma menos tiempo de trabajo producir el mismo producto.

Sin embargo, esta ley no es directamente observable para los capitalistas. En particular, el propósito consciente de la empresa capitalista es reducir, no el contenido de trabajo de sus productos, sino sus costos de producción. Esto puede realizarse si los capitalistas observan una reducción del precio de sus insumos o por la sustitución de un insumo más caro por otro más barato. Los capitalistas actúan sobre los precios y reaccionan a ellos, sin preocupación alguna por categorías de valor. 
Economía Informa núm. 383 noviembre - diciembre • 2013 | " " "

Cualquier modificación en los procesos de producción tiende a incrementar la productividad de la fuerza de trabajo afectando con ello el precio de las mercancías.

El ciclo del capital dinerario es presentado por Marx de la siguiente forma (Marx, Karl, (1982)):

$$
D---M--_{F T}^{M P}---P----M_{m}^{\prime M}----D_{d}^{\prime D}
$$

Donde $D$ es capital dinero adelantado.

$M$ es el capital productivo: Medios de producción (MP) y Fuerza de trabajo $(F T)$ que será consumido durante el proceso de producción.

$P$ es el proceso de producción

$M^{\prime}$ es el capital mercantil cuyo valor ha aumentado como consecuencia del trabajo excedente de los obreros. El valor total de estas mercancías puede dividirse por una parte en el valor de los medios de producción y de los salarios adelantados $(M)$, y por la otra en el plusvalor potencial a realizar $(m)$. $D^{\prime}$ representa el capital dinerario incrementado una vez que las mercancías han sido realizadas. $D^{\prime}$ puede dividirse en $D$ el capital dinerario adelantado al inicio del circuito y del plusvalor realizado.

A partir del ciclo del capital dinerario se define el ciclo de capital productivo de la siguiente manera:

$$
P----M_{m}^{\prime M}----D_{d}^{\prime D}---M_{F T}^{M P}--P
$$

Del ciclo de capital productivo se tiene lo siguiente:

a) Cuando se despliega el proceso de producción se tiene que la maquinaria y equipo de producción, así como las construcciones e instalaciones fijas que forman parte de los medios de producción adelantadas, participan como valores de uso íntegramente en el proceso de producción pero en el proceso de valorización sólo una parte de su valor original es recuperado.

b) Tanto las materias primas y auxiliares, al ser consumidas por la fuerza de trabajo empleada, transmiten en un solo ciclo de producción su valor. Por lo que se les define como capital circulante.

La diferencia entre las materias primas y auxiliares y la fuerza de trabajo no se observa en su proceso de transferencia de valor (rotación) sino en el proceso de creación de valor en tal sentido, la fuerza de trabajo además de reproducir su valor es capaz de generar un valor adicional mediante el consumo productivo que realiza tanto del capital constante fijo como del capital constante circulante. Este valor adicional constituye el plusvalor.

c) Cuando las mercancías son valorizadas el capitalista no se ve obligado a invertir la misma masa de valor para el segundo ciclo de producción, en tanto que el capital constante fijo no tiene que ser repuesto como valor de uso. En consecuencia el monto de capital dinera- 


\begin{abstract}
rio que el capitalista podría reinvertir se constituye tanto por el plusvalor que se invertiría (fondo de acumulación) como medios de producción, como por el valor del capital constante fijo recuperado (fondo de depreciación) por la venta de sus mercancías.

d) Los costos de producción dependen del desarrollo del proceso de producción. El cual a su vez determina los montos de capital dinerario que pueden constituir la inversión de capital. Tanto el ciclo de capital dinerario como el ciclo de capital productivo se condicionan mutuamente por lo que son expresión del movimiento del capital en general.
\end{abstract}

Tomando en cuenta que el proceso productivo está plenamente desarrollado es posible describir los procesos productivos como sistemas dinámicos gracias a lo cual se puede obtener una visión global de las estructuras productivas y del comportamiento tecnológico que siguen. La tasa de productividad de la fuerza de trabajo puede ser determinada dado que el obrero se ve sujeto a las leyes que enmarcan las condiciones de operación del sistema productivo en el cual, la productividad de éste aumenta conforme se incrementa la utilización de los elementos que lo componen.

Para comprender lo anterior es necesario fijar el hecho de que la renovación de los medios de producción es resultado de las formas particulares en que se desarrolla el proceso productivo, gracias a lo cual estamos en posibilidad de entender la naturaleza intrínseca del capital constante fijo y circulante.

El proceso productivo visto desde el punto de vista técnico, se desarrolla a partir de una economía mercantil, es decir los desembolsos de capital constante y variable así como la producción de mercancías producidas y vendidas registradas en el ciclo de capital, se establecen por relaciones cuantitativas monetarias que son las que dan contenido y viabilidad técnica, económica y social a los procesos productivos. Para los diferentes productores privados e independientes estas relaciones monetarias se presentan como datos a partir de los cuales planean y realizan su proceso de producción. Las diferencias cualitativas de proceso de rotación de capital se presentan como una diferencia cuantitativa desde el punto de vista de los precios. El desgaste físico de la maquinaria y la velocidad con que son transformadas las materias primas en el proceso de producción, gracias al trabajo productivo del obrero, es el determinante de los costos de producción de las mercancías finales. La renovación de los medios de producción en el tiempo a través de la venta del producto final no está exenta de cambios en los precios de los insumos, de las materias primas y de la maquinaria e instalaciones, los capitalistas tienen que prever dichos cambios mediante sistemas de actualización de sus precios sea mediante inventarios o con procesos de revaluación del capital constante fijo. El análisis de la rotación por tanto 
Economía Informa núm. 383 noviembre - diciembre • 2013 " ะ " "

debe de realizarse tomando escenarios de precios directos en la medida en que la evolución de los precios son reflejo de las condiciones de competencia en las cuales opera los diversos capitalistas. Cambios en los precios afecta el monto de plusvalor apropiado y la tasa de ganancia.

Dinámicamente la rotación del capital constante circulante se mide considerando los siguientes indicadores (Lange Oskar (1981) (a)).

a) Inventarios iniciales $N_{(0)}$. Esta relación establece la cantidad de materias primas y materias auxiliares introducida en el momento $t_{(0)}$ para que el proceso de producción inicie y tenga continuidad.

b) Coeficiente de utilización $l_{\text {(t) }}$ indica la tasa de cambio entre la cantidad de materias primas y materias auxiliares utilizadas en el momento $t$ y la cantidad de materias primas y/o materias auxiliares introducidas en el momento $t_{(\mathrm{O})}$ : Este indicador señala la fracción de materias primas y auxiliares que no ha transferido su valor de uso en el producto.

c) Coeficiente de decremento $\mathrm{P}_{(t)}$. Indica la relación que existe entre el decremento de la cantidad de materias primas y auxiliares en una unidad de tiempo de utilización y la cantidad de materias primas y auxiliares que originalmente se tenían, es decir: $(N(t)-\mathrm{N}$ $(t+1)) / N(o)$. Este indicador define la probabilidad de que el capital constante en el momento troj transfiera su valor de uso al producto final en el momento $t$.

d) Intensidad de decremento $\left(m_{(t)}\right)$. Muestra el consumo de materias primas y auxiliares que tiene lugar durante la unidad de tiempo $(t+1)$ y el número de materias primas y auxiliares que se tenían en el momento t. La intensidad de decremento puede interpretarse como la probabilidad de que el capital constante circulante durante $t$ unidades de tiempo transfieran su valor de uso al producto final durante la siguiente unidad de tiempo. Es decir $(N(t)-N(t+1) / N(t)$.

Con estos indicadores se puede calcular el número de objetos que pierden su valor de uso en una unidad de tiempo determinada, con lo cual se tiene el consumo del capital constante circulante en un periodo de tiempo. Los procesos de utilización del capital constante circulante pueden ser repentinos o graduales (continuos o discretos). La diferencia entre los inventarios iniciales y el consumo productivo durante una unidad de tiempo se denomina tiempo de reacción. En el caso en que el consumo sea repentino (total) el tiempo de reacción puede denotarse por un número real (positivo) individual; en el caso de un consumo gradual discreto se requiere de una secuencia de números reales para denotar el tiempo de reacción; en el caso de un proceso gradual continuo, se requiere de un intervalo continuo de números reales.

Designemos por medio de $t$ la unidad de tiempo (día, mes, año) y el tiempo máximo en el cual pueden ser utilizados dichos objetos en el proceso productivo $w$. En el año $t$ existirán, por consiguiente, objetos que fueron introducidos en el momento 1 , momento 2 , momento 3 , etcétera es decir: 


$$
\text { No(t-1), N1(t-2), N2(t-3) N3(t-w). }
$$

Sea $p(t)$ el coeficiente de decremento entonces el decremento de objetos en el año $t$ es igual a:

No $(p 1)=N 1$

No $(p 2)+N 1(p 1)=N 2$

$N o(t-1) p 1+\ldots+N n(t-w)=N n+1$

En un sistema continuo el anterior algoritmo se representaría de la siguiente forma:

$$
N_{0}(t)=\int_{0}^{t} N_{0}(t-\mathrm{t}) f(\mathrm{t}) d(\mathrm{t})
$$

Donde $f(\mathrm{~T})=-l(t)$ coeficiente de utilización.

La rotación del capital constante fijo depende de los siguientes factores; el deterioro físico de los bienes de capital y la obsolescencia; esta última se determina por el perfeccionamiento y generación de nuevos bienes de capital, por la aparición de nuevas técnicas de producción y de nuevos productos o bien por el cambio en la estructura de la demanda. La obsolescencia sin embargo es un fenómeno relativamente extraordinario y no se presenta de manera continua. En consecuencia el deterioro físico de los bienes de capital es el factor fundamental que determina la tasa de depreciación, este depende de la calidad de los materiales con los que fueron elaborados, de la calidad y eficiencia del sistema de generación y transmisión de energía empleado, de las condiciones de utilización en las cuales operan (cargas de utilización, condiciones atmosféricas, acción de sustancias químicas etc.), y de la intensidad de utilización. Estas referencias nos definen la vida útil del bien de capital es decir, el máximo tiempo en que puede funcionar un bien de capital sin que tenga que tener reparaciones que implique prácticamente su reconstrucción. Los bienes de capital con distintas edades no operan con heterogéneos niveles de eficiencia, una troqueladora construida en 2006 no funciona mejor que una troqueladora construida en 2005, lo que sucede es que la fracción de tiempo que perdurara en utilización el equipo construido de manera más reciente es mayor al del equipo más viejo.

Muchos economistas consideran que la perspectiva de Marx sobre depreciación es similar al enfoque de asignación contable del valor inicial del 
Economía Informa núm. 383 noviembre - diciembre • 2013 - " " "

activo durante su vida útil. Consideran lo anterior en la medida en que Marx utilizo patrones de depreciación lineal en sus ejemplos sobre rotación de capital constante fijo. Como bien explica Blair (Blair 1994) Marx consideraba la depreciación en función de los patrones de uso y características técnicas del equipo los cuales no necesariamente son lineales.

Así por ejemplo Marx explica:

Con el funcionamiento, y en consecuencia el desgaste, del medio de trabajo, una parte de su valor pasa al producto; otra queda fijada en el medio de trabajo y por ende en el proceso de producción: El valor así fijado disminuye constantemente, hasta que el medio de trabajo ha cumplido su tiempo de servicio y por tanto su valor se ha distribuido, en un periodo más o menos prolongado, entre una masa de productos que surgen de una serie de procesos laborales continuamente reiterados. Pero mientras todavía sea eficaz como medio de trabajo, o sea, mientras no hay que sustituirlo por un nuevo ejemplar del mismo tipo, siempre queda valor constante de capital fijado en él, mientras otra parte del valor fijado en él originalmente pasa al producto y por tanto circula como parte constitutiva del acopio de mercancías. Cuanto más dura el medio de trabajo, cuanto más lentamente se desgasta, más tiempo queda el valor constante del capital fijado en está forma de uso. Pero sea cual fuera el grado de durabilidad, la proporción en la que traspasa valor siempre está en razón inversa a su tiempo total de funcionamiento (Marx, Karl (1982), Vol. IV p. 190).

Marx concibió de manera muy concreta la idea hasta hoy precisada de patrones de eficiencia. Éstos deben ser interpretados como funciones de probabilidad que nos reflejan la posibilidad de que los bienes de capital durante $t$ unidades de tiempo trasfieran su valor de uso al producto final. Actualmente se consideran básicamente 3 patrones de eficiencia a saber: constante, lineal y geométrico.

1) El primero nos indicaría que durante toda la vida útil del bien de capital su capacidad de generar servicio no decae pero llegado un punto en el tiempo el bien de capital deja de funcionar y tiene que ser remplazado totalmente.

2) El segundo nos señala que la capacidad de generar servicio decae de manera constante durante toda la vida útil de los bienes de capital.

3) El tercero nos muestra que los bienes de capital al inicio de su vida útil pierden más rápido su capacidad de generar servicio y posteriormente, a la mitad de su vida útil, la pierden de manera lenta. ${ }^{15}$

A partir de los patrones de eficiencia se puede calcular un valor monetario a la pérdida de vida útil del capital constante fijo, estableciendo con ello los patrones de depreciación a saber: Lineal y geométrico.

\footnotetext{
${ }^{15}$ Cuando Marx analizó los patrones de transferencia de valor del capital constate fijo sólo se conocía el patrón de eficiencia lineal.
} 


$$
d l l_{\mathrm{t}}=\frac{1}{T}
$$

Donde $T$ es la vida útil del equipo.

$$
d G_{i}=\mathrm{d}(1-\mathrm{d})^{i-1} 16
$$

Donde $d l_{\mathrm{t}}$ y $d G_{i}$ son una unidad monetaria de inversión que se deprecian en forma lineal y geométrica respectivamente. Siendo $T$ la vida útil del capital constante fijo y $\delta$ es el parámetro de depreciación. Con estos patrones de depreciación pueden ser reintegrados los montos de dinero que se reciben por la recuperación del capital constante fijo, al venderse las mercancías, y si ocurriera una pérdida del poder de compra del dinero se tendría la posibilidad de calcular ésta independientemente de la depreciación asignada por efecto del patrón de eficiencia.

La rotación del capital constante fijo y circulante solo tiene sentido estudiarla si se vincula con la productividad del trabajo. La productividad del trabajo se define como la capacidad del trabajo para producir un determinado número de mercancías en una jornada. El incremento en la productividad de la fuerza de trabajo implica que el obrero en el mismo tiempo de trabajo ocupa de manera más intensa el capital constante fijo y transforma más materias primas y auxiliares, por tiempo de trabajo efectivo, en mercancías finales. "La forma en que el proceso de trabajo reviste al capital, en cuanto valor de uso, se objetiva en que los medios de producción operan como medios de producción de la capacidad de trabajo específica que actúan conforme a su naturaleza determinada", (Marx 1976 pp 305) La mayor relación capital trabajo no modifica la esencia del proceso de trabajo, pero si determina la interacción entre los elementos objetivos y subjetivos del mismo en los siguientes aspectos:

Crea tendencia a establecer niveles de especialización crecientes en las etapas parciales del proceso de producción y paradójicamente una simplificación progresiva de las actividades realizadas por los diferentes tipos de trabajo.

No sólo se libera las actividades de trabajo de la capacidad física de los seres humanos, sino que además, las operaciones de control, percepción y discernimiento paulatinamente se van independizando de la acción del hombre.

Se introducen nuevas actividades no necesariamente ligadas a la produc-

\footnotetext{
${ }^{16}$ El patrón de depreciación geométrico es equivalente al modelo de depreciación de balance de doble declinación es decir, la cantidad monetaria asignada por depreciación es un porcentaje constante del valor del activo del año anterior. Aunque la cantidad monetaria asignada a la depreciación cambia cada año el porcentaje permanece constante.
} 
Economía Informa núm. 383 noviembre - diciembre • 2013 " ะ " "

ción de plusvalor pero necesarias para su realización tales como administración, mantenimiento, control del proceso, contaduría y pagos, servicios al cliente, etc.

\begin{abstract}
Lo que el tiempo de trabajo vivo produce de más no es reproducción sino nueva producción de valores. Que a la vez se conserve el tiempo de trabajo contenido en la materia prima no se debe a la cantidad sino a su calidad como trabajo en general; esa calidad universal no es una calificación especial del mismo - no es trabajo específicamente determinado- (...) el capital no paga por esa calidad que la ha comprado en el intercambio con el obrero. (Marx (1976), pp. 305).
\end{abstract}

La planeación de los requerimientos de trabajo en los procesos de producción es posible establecerlos, independientemente de las características del trabajo concreto que se despliega, a partir de describir las llamadas operaciones unitarias $^{17}$. La normas de productividad de la fuerza de trabajo pueden ser estudiadas considerando que el obrero se ve sujeto a las leyes que enmarcan las condiciones de operación del sistema productivo en el cual la productividad de ésta aumenta conforme se incremente la utilización de los elementos que lo componen, por ende la norma de productividad de la fuerza de trabajo será una función de la cantidad de producto generado dado el sistema de producción utilizado y de las operaciones unitarias a las que se ve sometido. Esta norma de productividad es conocida como curva de aprendizaje dicha curva estima que la cantidad de horas de mano de obra directa requeridas para producir $1+n$ unidades de mercancías finales es menor en un porcentaje $x$ al requerido para producir la primera unidad. Lo anterior puede ser expresado de la siguiente manera:

$$
Y x=K x^{n}
$$

Donde $Y x=$ número de horas de mano de obra directa requerida para producir la unidad $x$.

$K=$ el número de horas de mano obra directa requerida para producir la primera unidad $x=$ el número de unidades a producir.

$n=$ parámetro dependiente de la curva de aprendizaje/porcentaje de reducción de horas hombre requerida por unidad de producto.

\footnotetext{
${ }^{17}$ Una operación unitaria puede definirse como un área del proceso o un equipo donde se incorporan materiales, insumos o materias primas y ocurre una función determinada, son actividades básicas que forman parte del proceso. Por ejemplo, la producción de pulpa o el descortezado en una fábrica de papel, o la destilación en un proceso de elaboración de productos químicos.
} 
Entonces el número de horas hombre acumulado para producir $N$ unidades puede ser formulado de la siguiente manera:

$$
\begin{gathered}
T_{N}=Y_{1}+Y_{2}+\ldots+Y_{N}=\sum_{X=1}^{n} Y_{n} \\
T_{N}=\int_{0}^{N} K x^{n} d x
\end{gathered}
$$

El análisis del proceso de producción como un proceso dinámico nos posibilita describir el consumo productivo tanto de los objetos de trabajo, de los insumos utilizados y de la fuerza de trabajo. La constancia en los parámetros productivos deriva tanto de la relación técnica del proceso productivo del propio sistema, como de la relación social que le da contenido y viabilidad. Las trayectorias tecnológicas, definidas éstas sobre la base de sistemas de operación unitarios, marcan las normas sociales de productividad de la fuerza de trabajo la cual se asocia necesariamente a las funciones de probabilidad normal. El comportamiento de los diversos capitales privados e independientes presenta variaciones respecto a la media social de la operación unitaria. A escala social, el control del proceso productivo de cada capital privado e independiente se determina por una relación funcional más que por una relación óptima de transformación. Esto no implica que no se realice la optimización de los procesos de transformación de las materias primas y auxiliares para cada capital privado independiente. La optimización se expresa en este nivel cuando se logra la armonización, y sincronización del proceso productivo, aspectos que posibilitan una distribución espacial homogénea de la tasa de transformación de las materias primas y auxiliares. Lográndose lo anterior cada capital privado e independiente es capaz de discernir la inserción de cambios tecnológicos orientados a la intensificación y extensión de la jornada de trabajo. Por tanto, cualquier cambio tecnológico introducido se deberá reflejar en una disminución de la cantidad de horas trabajadas por unidad de mercancía producida, circulada y distribuida.

Podemos afirmar que la competencia intercapitalista establece la dinámica de expansión de los diversos mercados a partir de la capacidad de los capitales privados e independientes para aumentar la productividad de la fuerza de trabajo Conforme se expanden y especializan los mercados se establecen articulaciones y patrones de competencia intracapitalistas que definen espacios de acumulación (nacionales e internacionales) los cuales determinan las condicionantes sociales para incrementar la productividad de la fuerza de trabajo. 
Economía Informa núm. 383 noviembre - diciembre • 2013 | " " "

\section{Rotación de Capital y formación de valores y precios de mercado}

Como hemos visto, el análisis del intercambio de mercancías según el trabajo socialmente necesario invertido en su producción pone énfasis en el estudio y determinación del consumo productivo por parte de la fuerza de trabajo de los elementos objetivos del proceso de trabajo a saber: materias primas, materias auxiliares, herramientas, maquinaria, etcétera, permite no sólo la modificación material del capital invertido sino es el incremento del valor. En este nivel de análisis el proceso de valorización abstrae en principio la distribución de la plusvalía con base a los montos de capital invertido, centrando su atención en el máximo nivel de plusvalía que cada capitalista será capaz extraer del proceso de producción es decir, analiza el proceso de producción como un proceso de valorización. Este proceso no puede ser entendido sin considerar los principios que regulan la demanda social la cual en principio determina, las características tecnológicas de los diversos productores que satisfacen un mercado y las condiciones de competencia que imperan. En consecuencia los capitalistas tienen que prever las condiciones de cambio de corto plazo que se manifiestan tanto en el precio de sus insumos y materias primas como respecto a los productos que pretenden vender en el mercado. Esto implica entonces, que la satisfacción de esta necesidad social (sea como medio de producción, de subsistencia o bienes de consumo para la clase capitalista) supone la existencia de una oferta social la cual se conforma por diferentes capitales con concentraciones de capital también desiguales.

La producción anual de estos $n$ productores determina lo que Marx define como el valor de mercado Este se define como la media de los valores individuales de las mercancías producidas en una esfera. Existirán capitales que tengan mejores condiciones de producción, habrá otros que coincidan con las condiciones medias de producción y otros que presentan condiciones inferiores a la media de producción. Cuando la oferta de mercancías al valor medio, es decir el valor medio de la masa ubicada entre ambos extremos, satisfacen la demanda habitual, las mercancías cuyo valor individual se halla por debajo del valor de mercado realizaran una plusvalía extraordinaria o plusganancia, mientras que aquéllas cuyo valor individual se halla por encima del valor de mercado no pueden realizar una parte del plusvalor contenida en ellas. A determinados precios, un tipo de mercancía puede ocupar un lugar determinado en el mercado; el lugar sólo sigue siendo el mismo, en caso de cambios de los precios, si el precio superior coincide con una menor cantidad de mercancías 
(demanda menor) y el precio más bajo con una cantidad de mercancías mayor (demanda mayor). En cambio, si la demanda es tan intensa que no se contrae cuando el precio resulta regulado por el valor de las mercancías bajo las peores condiciones, éstas determinan el valor de mercado. Esto sólo puede ser posible cuando la demanda supera a la demanda habitual, o la oferta desciende con respecto a la demanda habitual. Por último, si la masa de las mercancías producidas es mayor que las que encuentran salida a los valores medios de mercado, las mercancías producidas bajo las mejores condiciones regulan el valor de mercado (Marx, Karl (1984), Vol. vi, p. 226).

Si la demanda social es la habitual las mercancías se venden a su valor de mercado. En cambio, si la cantidad es menor o mayor que la demanda que ella existe, se manifiestan divergencias en el precio de mercado con respecto al valor de mercado (Marx, Karl (1984), Vol. vi, p. 234).

En consecuencia desde la perspectiva de la demanda hay ciertas magnitudes de necesidades sociales que requiere para su satisfacción, una cantidad determinada de un artículo en el mercado. Pero la determinación cuantitativa es totalmente elástica y oscilante. Su carácter fijo es aparente (Marx, Karl (1984), Vol. vi, p. 238).

Los capitales operan en un entorno cambiante el cual enfrentan mediante y a través de sus inventarios. Esto puede cambiar en función del control del mercado que tienen tanto como oferentes de mercancías como de demandantes de insumos intermedios y bienes de capital. Los capitales entonces determinan su ganancia sobre la base del precio de mercado que históricamente han enfrentado o el que prevén tendrían que afrontar. La forma como los diversos capitalistas registran lo anterior es mediante la denominada contabilidad empresarial. En ésta, el ciclo de capital puede ser analizado a partir de las hojas de balance ya que describen las fuentes y usos del capital (consumo de capital por parte de la fuerza de trabajo). Las ganancias reportadas son expresión del plusvalor en la medida en que reflejan indirectamente el tiempo de trabajo individual gastado en la producción. Los balances de pérdidas o ganancias dan información de la formas en que se expande el proceso de producción y, en segundo lugar de las variaciones de precios relativos a los cuales se sometido el capital al comprar el capital constante (fijo y circulante) destinado a la producción. Las hojas de balance empresarial deben y pueden ser utilizadas como una base de las fuentes y uso del capital de esta forma, se puede comprender como las ganancia capitalista son los incrementos netos de capital para el periodo e incluye tanto retiros del esta ganancia para ser repartidos como beneficios, sueldos de los trabajadores no productivos e incrementos del capital físico invertido. 
Economía Informa núm. 383 noviembre - diciembre • 2013 ㅁ

La conformación de un sistema de contabilidad basado en la determinación del precio de mercado respecto a uno en valores individuales a partir de los datos obtenidos en el ejemplo desarrollado es el siguiente.

\section{Determinación del precio del mercado con inventarios}

\section{Resultados contables de materiales usados}

Total de materiales usados $=$ Inventarios iniciales + Compras + Gastos de flete. Total de Capital constante usado = Capital constante circulante en materias primas $t-1(p$ $t-1 * q t-1)+$ Capital constante circulante de materias primas $t+n(p t+n * q t+n)$ (en función de la norma de productividad) + Gastos de flete.

Costo de materiales usados $=$ Costo Total de materiales usados año i - Inventarios finales.

Costo de capital circulante usado = Total de Capital constante circulante usado de materias primas - inventarios finales de capital circulante.

Resultados contables de inventario de trabajo en proceso

Costo total de producción $=$ Costo de materiales usados + Trabajo directo $($ salarios) + Gastos generales de producción (Trabajo indirecto + gastos de energía refacciones gastos de seguros e impuestos + depreciación de planta y equipo)

Costo total de producción = Capital constante circulante usado (materias primas y auxiliares) + capital variable + capital constante fijo usado (depreciación) + gastos de seguros e impuestos (capital improductivo)

Costo de bienes manufacturados $=$ Costo total de producción - Inventarios finales de trabajo en proceso

Costo de bienes manufacturados (precio de costo bienes manufacturados) = Capital constante circulante usado (materias primas y auxiliares) + capital variable + capital constante fijo usado (depreciación) + gastos de seguros e impuestos (capital improductivo) - Inventarios finales de trabajo en proceso 


\section{Resultados contables de Inventarios de bienes finales}

Costo de Bienes de bienes disponibles para la venta (precio de costo bienes disponibles para la venta) $=$ Costo de bienes manufacturados + Inventarios iniciales de bienes finales.

Costo de Bienes de bienes disponibles para la venta (precio de costo bienes disponibles para la venta $)=$ Precio de costo bienes manufacturados + inventarios iniciales de bienes finales .

Costos de bienes vendidos $=$ Costo de Bienes de bienes disponibles para la venta - Inventarios finales de bienes terminados.

Costos de bienes vendidos (precio de costo de bienes vendidos) = precio de costo bienes disponibles para la venta - Inventarios de bienes finales de bienes terminados.

Existe una diferencia entre el costo de producción y el costo de los bienes vendidos por efecto del comportamiento de inventarios y los gastos necesarios, pero improductivos, a efectuar para que la producción se realice como mercancías.

En primer lugar la constitución de los inventarios modifica la valoración de la masa de ganancia obtenida dado que se rompe la visión del proceso de producción como un proceso continuo. En consecuencia, las ventas que se van realizando al término de cada proceso de producción relacionan ciclos de producción diferentes que en condiciones de estabilidad, tanto de los precios relativos, como del comportamiento de la demanda social, no altera la obtención de plusvalía. En caso contrario, el manejo de inventarios está orientado a controlar las modificaciones temporales en el sistema de precios relativos. ${ }^{18}$ Los capitales que presentan un mayor nivel de eficiencia productiva serán los más aptos para mantenerse en el mercado, ante una disminución del precio de mercado de sus mercancías o bien por un incremento en los precios de sus materias primas y auxiliares. Si el comportamiento de los precios relativos (en este caso hablamos de precios de mercado) no es temporal sino permanente pueden generarse modificaciones en la productividad del trabajo a saber: Si suben los precios de las materias primas y disminuye la producción en la misma proporción en que se

\footnotetext{
${ }^{18}$ Marx al respecto señala lo siguiente: “1) Cuando los acopios de materia prima que se hallan en depósito son importantes, contrarrestan el aumento del precios originados en el foco de producción de la materia prima; 2) cuando la productos semielaborados o las mercancías terminadas que se hallan en el mercado gravitan mucho sobre el mismo, impiden que el precio de las mercancías terminadas y los productos semielebarorados aumenten en proporción al precio de su materia prima.A la inversa ocurre en el caso de un descenso de precio de la materia prima, el cual, bajo circunstancias en lo demás iguales, eleva la tasa de ganancia. Las mercancías que se hallan el mercado, los artículos que aún se hallan el a etapa de elaboración y los acopios de materia primas se desvalorizan, y de esa manera se contrarresta el simultáneo ascenso de la tasa de ganancia." (Marx, Karl (1984), p. 139).
} 
Economía Informa núm. 383 noviembre - diciembre • 2013 | " " "

incrementan los precios, entonces la cantidad física de mercancías finales por hora hombre trabajada disminuirá y viceversa. La medición del plusvalor en términos de horas de trabajo excedente aun cuando se considere la contabilidad empresarial puede ser medida a partir de la determinación de la productividad del trabajo en términos dinámicos Asimismo, la depreciación de la maquinaria y equipo aparece como una asignación contable, no se explican la naturaleza de esta asignación con lo cual si la contabilidad no es resultante del desarrollado en un proceso de producción podría presuponerse, como de hecho se preconcibe en los esquemas de contabilidad estándares, que la asignación por depreciación es un rubro contable ajeno al proceso de producción. Las metodologías financieras para evaluar la rentabilidad a obtener al introducir un bien de capital nuevo, usando el concepto de valor actual neto, son ejemplo de lo antes dicho.

Por otra parte en el esquema contable que estamos analizando se consideran los gastos improductivos como parte del costo de producción pero necesarios, que tienen que realizarse al desplegarse el proceso de valorización a saber: trabajo administrativo, gasto de seguros y fletes.

Por último no se consideran, como parte del proceso de producción, gastos que son productivos como son los gastos del mantenimiento de la maquinaria y equipo, los gastos para mantener en condiciones adecuadas los inventarios y los gastos del trasporte que se ejercen para la realización de las mercancías o para la compra de insumos. Estos gastos son considerados como gastos generales.

El problema fundamental que se presenta es analizar a que precios se deben tasar los insumos y las mercancías vendidas ante la existencia de un sistema de inventarios. Los demás problemas pueden ser relativamente fácilmente resueltos si se reasigna la estructura de contabilidad en forma tal que ésta refleje el proceso de producción. Respecto al primer problema Rober Bryer (Bryer, 1999) considera que el análisis del ciclo de capital permite aplicar las reglas de valuación de la contabilidad empresarial las cuales las sintetiza de la siguiente manera: i) el capital en la esfera de la circulación es valuado a su menor costo de mercado ii) el capital en la esfera de la producción es valuado al menor costo de la cantidad de inversión recuperable iii) el capital monetario que se encuentre sea en la producción o en la circulación debe ser valuado a su costo histórico y el capital no monetario (débitos o créditos) debe ser valuado a su costo de remplazamiento.

La competencia, las oscilaciones de los precios de mercado que corresponder a las oscilaciones de la relación entre oferta y demanda, intentan reducir constantemente a esa medida la cantidad global del trabajo empleado para cada tipo de mercancía. 
En la relación entre oferta y demanda de las mercancías se reitera, en primer lugar, la relación entre valor de uso y valor de cambio, entre mercancía y dinero, entre comprador y vendedor; en segundo lugar, la relación productor y consumidor, pese a que ambos puedan estar representados por terceros comerciante (Marx, Karl (1984),Vol. 6, p. 243).

El contenido de trabajo de las mercancías no es observable de manera directa por los productores; en particular, el propósito consiente de los capitalistas es reducir sus costos de producción no el contenido de trabajo de sus productos. Los capitalistas actúan sobre los precios y actúan sin preocupación alguna por categorías de valor. La conexión sistemática entre precios y valores debe entenderse considerando los costos de producción y su incidencia en el contenido de trabajo. En un escenario de precios valores de corto plazo - en su transcurso la producción, y en consecuencia la oferta de productos no puede cambiar substancialmente-, a la oferta y demanda se les puede considerar como magnitudes dadas y definidas, el equilibrio se garantizaría por la existencia de un acervo de inventarios. En este escenario empieza a vislumbrarse la importancia de la tasa de ganancia como medida de rentabilidad del capital dado que el plusvalor no representa para el capitalista ningún costo. La posibilidad de adecuar sus precios conforme a una tasa de ganancia se presenta como un fenómeno aleatorio que se le impone a cada capitalista individual a través de la competencia. De no existir ésta las diferentes ramas de una economía tendrían diferentes tasas de ganancia en correspondencia con diferente composición orgánica de capital y por sus diferencias en sus tiempos de rotación. La competencia implica que la tasa de ganancia deberá ser directamente proporcional a la magnitud del capital invertido. Al conformarse la categoría de precios de costo desaparece para el capitalista la diferencia entre capital variable y capital constante. Los precios de costo son los mismos para desembolsos de capital de igual magnitud por muy diferentes que puedan ser los valores y plusvalores producidos. Esta igualdad en el precio de costo constituye la base de la competencia de las inversiones de capital mediante las cuales se tiende a establecer la ganancia media.

Consideremos por último en este apartado que el sistema de precios refleja además la distribución de la plusvalía entre capitalistas. Esta deriva de la necesidad de reconocer que las mercancías se venden como capital y en consecuencia el monto de ganancias que obtendría será función asimismo del capital total desembolsado una vez que los capitalistas se sujeten a los estándares de productividad que el mercado que satisfacen les marque.

Cabe señalar que este escenario supone la existencias de tiempos de trabajo socialmente necesarios para la producción de lo contrario ningún capitalista 
Economía Informa núm. 383 noviembre - diciembre • 2013 | " " "

podría determinar el monto de plusvalía que estaría habilitado a prescindir o a recibir dentro del mercado. En ambos escenarios analíticos todos los elementos materiales que son económicamente necesarios para la producción sufren una bifurcación.

Ellos son integrados a la producción como formas físicas heterogéneas pero al mismo tiempo son constituidos al proceso de producción teniendo una forma homogénea monetaria (valor). El sistema capitalista no trasciende esta contradicción dado que sólo razona la forma monetaria reduciendo el problema del proceso de trabajo a una mera cuantificación de desembolsos monetarios en el tiempo. Cabe señalar que esto explica el porqué los economistas neoclásicos consideran en el mejor de los casos la esfera de la producción como un dato técnico (coeficientes técnicos) o bien, realizan mediciones físicas considerando funciones de producción a precios constantes sin explicar la naturaleza social del proceso de producción. Consecuentemente todos los insumos y productos obtenidos por la diversidad de procesos productivos son medidos en términos monetarios. Dado que el trabajo también es un costo de producción las capacidades heterogéneas del trabajo como insumo son medidas en términos de dinero (salarios) esto es un término ideal de conmensurabilidad del valor dinero en términos del producto.

Cuando las mercancías se intercambian no como productos del trabajo sino como productos del capital se refuerza la necesidad de acrecentar la explotación del trabajo mediante formas de producción en donde se desligue el control del proceso de trabajo por parte del obrero. Este nuevo escenario no puede ser desplegado sin la existencia del tiempo de trabajo socialmente necesario y el desarrollo del régimen de producción de plusvalía relativa. La categoría de tiempo de trabajo socialmente necesario expresa en este contexto las relaciones tecnológicas que son establecidas dentro de los diversos procesos de producción. La venta de las mercancías como producto del capital supone asimismo, para que sea conmensurable, un sistema contable que refleje el proceso de producción de cada capitalista y del conjunto de ellos. Las categorías contables permiten conceptualizar momentos específicos del proceso dinámico de la producción y al mismo tiempo les permiten a los capitalistas tener criterios de reasignación del plusvalor considerando su necesidad de reproducción.

La determinación de sistema de precios de producción implica una modificación en las estructuras de contabilidad. En este escenario el precio valor de la mercancía se modifica pasando de $C c f+C c c+C v+P$ a $C c f+C c c+C v+\left(1+g^{\prime}\right)$ donde $g$ ' es la tasa de ganancia media. Para el capitalista el precio de las mer- 
cancías es su precio de costo. Esto implica que ahora el precio de su mercancía para que permita la reproducción del capital ya no es su valor sino su precio de costo es decir $\mathrm{Ccf}+\mathrm{Ccc}+\mathrm{Cv}$. En consecuencia la masa de mercancías producidas contiene diversas cantidades de plusvalor por unidad de tiempo. La formación de precios de producción implica que las masa de plusvalía realizada por cada capitalista dependerá de su monto de inversión es decir a igual inversión de capital le debe de corresponder igual nivel de ganancia. La ganancia se presenta entonces como la forma transfigura de la plusvalía. La necesidad de establecer una tasa media de ganancia se explica por el pleno desarrollo del intercambio los cual implica la concatenación de ciclos de compra y venta de diversos capitalistas. Esta concatenación determina a su vez la reproducción social de los capitales en el sentido de que cualquier modificación en la oferta o demanda de alguno de ello altera el proceso de producción de los otros y por ende el proceso de explotación de la fuerza de trabajo. En consecuencia la necesidad de redistribuir el plusvalor social a partir de la formación de los precios de producción requiere necesariamente el establecimiento pleno de los sistemas de producción a fin de determinar el monto de plusvalía que cada capitalista recibe o será capaz de proporcionar.

Para los diversos capitales privados e independientes la tendencia a que las mercancías se vendan a sus precios de producción aparece como modificaciones en los precios del capital constante fijo (revaluación) y circulante. Estos cambios se verán reflejados en sus esquemas contables a partir de los precios de mercado ante los cuales opere como productor o como demandante de capital constante. La existencia o inexistencia de competencias intracapitalista provocaran que este proceso se acelere o bien se retarde. De ser lo primero, los capitales tendrán que modificar sus condiciones de producción las cuales en un primer momento, no se verán afectadas. En un segundo momento tendrán que buscar elevar la tasa de explotación de la fuerza de trabajo haciendo modificaciones en la organización de sus procesos de producción a fin de aprovechar las nuevas condiciones de precios relativos buscando acentuar la intensificación del trabajo. Una vez agotado lo anterior la tendencia a la igualación de la tasa de ganancia orienta las decisiones de inversión en capital constante fijo con el objetivo de acrecentar la productividad del trabajo. El proceso descrito determina la acumulación de capital y tiene como sustento la gestión de éste sobre la fuerza de trabajo orientada a la obtención de plusvalor. El proceso de valorización es por tanto el eje de la acumulación y se ejerce independientemente del sistema de precios en el cual se desarrolle la competencia capitalista. La medición de la productividad del trabajo en términos de 
Economía Informa núm. 383 noviembre - diciembre • 2013 | " " "

tiempo de trabajo (necesario y excedente) a nivel de un capital individual se realiza a partir de las condiciones de operación de los sistemas productivos. Los capitales no tienen conciencia del tiempo de trabajo contenido en el capital constante fijo y circulante que utilizan en sus procesos de producción pero sí tienen conocimiento del valor producido por sus obreros a través del uso de este capital. Entonces los datos contables que dan razón a la cantidad de insumos utilizados y la cantidad de desgaste de la maquinaria por unidad de tiempo de trabajo constituyen la medida directa del valor producido por los obreros. El cálculo anterior es realizado por cada capitalista si no lo hiciese estaría incapacitado para tomar decisiones de inversión de capital ante cambios en sus precios (valores) relativos que enfrenta al desplegar su proceso de producción.

\section{El uso de la contabilidad marxista para analizar la acumulación de capital}

Se ha mostrado que el marco conceptual marxista es capaz de incorporar integralmente las métodos de evaluación actuales del capital constante fijo y circulante aplicados en la contabilidad de las empresas sin romper con ello su perspectiva del valor lo cual cabe subrayar, las otras teorías no pueden realizar de manera sistémica. Por ello, se demuestra que el desarrollo del modelo dinámico expuesto puede ser aplicado de manera directa mediante el análisis de la contabilidad empresarial tomando en cuenta las siguientes consideraciones:

Las reglas de contabilidad generalmente aceptadas razonan que los estados contables deben ser reflejo de los recursos y obligaciones de una empresa, los flujos financieros son expresión del comportamiento de la empresa. Para Marx la contabilidad se ciñe a la evaluación del monto de plusvalor apropiado por los capitalistas en función del capital desembolsado.

Los esquemas contables no consideran la relación entre procesos de producción y contabilidad, en la teoría marxista la contabilidad es la medición del trabajo social por tanto la contabilidad no se puede considerar sin el análisis de la producción.

La ganancia es resultado de la producción y venta de mercancías. Deduciendo los costos de producción al precio de venta de mercancías se tiene una sanción social de la eficiencia de la empresa. Las técnicas contables y la teoría marxista consideran los mismos elementos.

La rentabilidad de una empresa debe medirse en capital monetario corriente pues evalúa la eficiencia en periodos de tiempo determinados los cuales son determinados por el ciclo de capital industrial, coincidiendo con ele- 
mentos de la contabilidad empresarial que considera que la ganancia es dinero corriente no equivalente monetario.

La relación entre ciclo de producción y circulación es gestionada a través de la conformación de los inventarios de materias primas y auxiliares y de las mercancías finales. Las modificaciones de precios son consideradas por los sistemas LIFO, FIFO y sólo pueden ser comprendidas mediante el análisis de la dinámica de la producción capitalista y la rotación de capital. El análisis de la circulación de capital es consistente con las reglas generales de valuación de activos por parte de la contabilidad.

La rotación del capital constante fijo no es la asignación contable del valor inicial del activo durante su vida útil sino que depende de su patrón de eficiencia. Éste se determina por la capacidad de los medios de trabajo para mantener el proceso de producción en forma continua y permitir con ello el máximo nivel de explotación de la fuerza de trabajo.

Las características sobre la rotación de capital se analizan en función del gasto de trabajo productivo. La teoría Marxista logra definir con precisión lo que es trabajo productivo e improductivo, en función de si el trabajo logra la recuperación del capital constante fijo y circulante mediante su consumo productivo. La rotación de capital entonces se convierte en un tema de análisis central para estudiar la rentabilidad del capital.

La contabilidad empresarial define con claridad las características de las mercancías que forman parte del precio (valor) de las mercancías finales permitiendo determinar los ciclos de compra y venta tanto mercancías destinadas al consumo productivo como aquéllas que se destinan al consumo final. Si se tiene una agregación de estos gastos para lo n capitales privados e independientes que mantenga esta distinción es factible analizar la acumulación de capital para $n$ capitalistas considerándolos como un capital individual.

\section{Conclusiones}

Las críticas al sistema de evaluación de flujos financieros se centran fundamentalmente en el supuesto de que los empresarios manejan los mismos escenarios de incertidumbre en donde el comportamiento de la demanda y la tasa de rendimiento esperada son acotados por el mercado (es decir son variables exógenas a la empresa); con ello el fenómeno de la competencia queda reducido a un problema de racionalidad de los agentes productivos. La metodología del valor presente en términos prácticos se aplica para medir el efecto de las economías de escala y del cambio tecnológico. La forma de utilización es la siguiente: 
Economía Informa núm. 383 noviembre - diciembre • 2013 | " " "

Los flujos de ingresos y egresos se calculan para diferentes niveles de producción de la planta. El valor presente de los flujos de tesorería para cada nivel de producción se compara, y si el valor presente se incrementa más que proporcionalmente con la escala (o con la introducción de la nueva tecnología) se inferirá que existen economías de escala, o que el efecto del cambio tecnológico es positivo. Podemos afirmar que los estudios sobre el comportamiento de los costos que tradicionalmente se han realizado por la teoría financiera neoclásica se han orientado a dar razón de la distribución de los recursos (factores de producción) entre un número de industrias distintas cada una de las cuales utiliza una parte de los recursos totales y a estudiar el comportamiento en la producción de una mercancía especifica ante la variación absoluta de los factores. La contradicción fundamental de la contabilidad como disciplina es que por un lado es capaz de explicar aspectos de la realidad concreta tales como el patrimonio empresarial, el endeudamiento de las empresas y su capacidad de pago etc. y, al mismo tiempo los modelos existentes de contabilidad actualmente utilizados basan por un lado su cuantificación de modelos estandarizados de costos y por otra parte los estados financieros se orientan a las necesidades de los inversionistas, no integrados a la gestión de las empresas. Ambos objetivos no consideran las particularidades de los procesos productivos. Aún más esta tendencia de los métodos contables modernos se inserta en la preponderancia del capital financiero sobre el capital productivo y mercantil la cual se expresa en imponer criterios de eficiencia a partir de considerar el dinero como un activo. Tal situación lleva a deformaciones sobre la descripción de la realidad operativa de las empresas capitalistas mediante la denominada contabilidad creativa, la cual en términos llanos y simples implica supone registrar utilidades mediante la modificación de los registros. Esta práctica es responsable en gran parte de la reciente crisis financiera del 2008 cuyo antecedente del manejo fraudulento de la contabilidad es el caso de la empresa Enron.

Dadas las insuficiencias observadas tanto a nivel teórico como contable, en las estructuras de contabilidad — referentes a la medición de la rentabilidad y la conceptualización y registro de consumo de productivo de materias primas y auxiliares y del capital constante fijo- el ciclo de capital se convierte en una opción más eficiente que la elaboración de funciones de producción y de esquemas contables de interdependencia sectorial en la medida en que: es capaz de analizar y describir el proceso de producción y las interrelaciones que lo definen. Explica la producción como un proceso de valorización integrando para tal fin la explicación de la ganancia capitalista con el proceso de trabajo y en particular con el uso de la fuerza de trabajo y su productividad. 
Se puede incorporar analíticamente la existencia de múltiples capitales con diferentes concentraciones de capital en un mismo mercado. En función de lo anterior es factible observar las particularidades de los procesos contables que son utilizados por diversos capitales, derivados de la concentración de capital que tienen, como los métodos de depreciación del capital constante fijo que utilizan a partir de los patrones de eficiencia de la maquinaria y equipo y del uso real de éstos.

Se pueden articular las presentaciones contables que dan razón del comportamiento de los inventarios sin perder la descripción del proceso de producción como un proceso de valorización. Es decir, las ventas que se van realizando al término de cada proceso de producción relacionan ciclos de producción diferentes que en condiciones de estabilidad, tanto de los precios relativos, como del comportamiento de la demanda social, no altera la obtención de plusvalía. En caso contrario, el manejo de inventarios está orientado a controlar las modificaciones temporales en el sistema de precios relativos. Por ello, la gestión del capital sobre la fuerza de trabajo y de su productividad se puede representar mediante la organización de la producción y la contabilidad de los gastos a fin de determinar la ganancia como un proceso de obtención del plusvalor. La distribución del plusvalor no invalida el proceso de producción como proceso de valorización sino que lo incluye dentro de la órbita del proceso de competencia capitalista en un entorno intra sectorial. Al respecto, se mostró que la competencia capitalista, en el momento en que aparece la necesidad de uniformar la tasa de ganancia para los diversos capitales, resulta en un esquema contable en el cual dado el capital constante y variable en términos de precios directos (precios determinados por el contenido de trabajo) es igual a la suma de capital constante más capital variable más una tasa de ganancia determinada por el efecto de la distribución de la plusvalía entre los diversos capitalistas. Los cambios en el sistema de precios derivados de la tendencia a la igualación en la tasa de ganancia inducen modificaciones en el consumo de las diversas mercancías que son utilizadas como capital en los procesos de producción. En función de ello, se pueden presentar procesos de adecuación en los sistemas técnicos que posibiliten a los diversos capitalistas utilizar aquellas combinaciones técnicas que les permitan obtener el máximo de plusvalía. En este sentido podemos afirmar que la composición del valor del capital expresa, por un lado, los cambios autónomos determinados por las condiciones de mercado y por otra parte, las condiciones de reproducción del sistema en su conjunto. En consecuencia los cambios en la composición en valor del capital, y su efecto en la tasa media de ganancia, no puede ser 
Economía Informa núm. 383 noviembre - diciembre • 2013 | " " "

evaluada sin considerar que los precios relativos son resultado de un proceso de articulación intersectorial que en el tiempo y en el espacio va condicionando determinados patrones tecnológicos entre las actividades productivas. El concepto de acumulación queda claramente definido dado que se puede establecer los efectos que tienen los cambios en los precios relativos en las condiciones de producción y de valorización, con ello se logra determinar cuándo las capitales están en reproducción simple o reproducción ampliada.

\section{Bibliografía}

Aglieta M. (1976), Regulación y crisis del capitalismo, México, Siglo XXI.

Bryer R.A. (1994), "Why Marx'slabour theory is superior to the marginalist theory of values the case from modern financial reporting." UK, Critical perspective on accounting N0 5 pp 313-340.

Bryer R.A. (1999), "A Marxist critique of the FASB conceptual framework. UK". Critical perspective on accounting, No 10 pp. 551-589.

Bryer R.A. (2002), Accounting and control of the labour process, UK, Mimeo.

Bryer R.A. (2005), "Marx accounting and the labour theory of value: a critique of Marxist economics." UK, Mimeo, Critical perspective on accounting.

Conesa Duarte A.1996, El método operativo contable y los principios de contabilidad-Cuadernos de Estudios Empresariales núm. 6 servicios de Publicaciones, UCM, Madrid.

Foley Duncan K. Piruz Alemi (1997), The Circuit of Capital, U.S. Manufacturing and Non-Financial Corporate Business Sectors, 1947-1993. usa, Mimeo,

Fraumeni Barbara (1997), The measurement of depreciation in the U.s. National Income and Product Account. Survey of current business, Julio, pp. 7-23.

Gabriel Jacob Velandia Pacheco (2009), "Un concepto sobre la cientificidad de la contabilidad" Adversia (julio-diciembre), pp. 110-127, Universidad de Antioquia

Jorge Tua Pereda (1998), "Evolución del concepto de Contabilidad a través de sus definiciones" xxv años de Contabilidad Universitaria en España, homenaje al Dr. D. Mario Pifarré Riera. Ministerio de Hacienda, Instituto de Planificación Con-table, Madrid, 1988, pp. 895 a 956.

Kanawaty G. (1998), Introducción al estudio del trabajo. México. OIT - Limusa.

Lange, Oskar. (1981) (a), Economía Política II, México, Fondo de cultura Económica.

Lange, Oskar. (1981) (c), Los todos y las partes. Una teoría general de conducta de sistemas, México, Fondo de Cultura Económica. 
Liliana Fernández Lorenzo y Alejandro Barbei (2010), Un análisis reflexivo sobre medición contable, Mimeo Facultad de Ciencias Económicas, Universidad Nacional de La Plata.

Madala G. S. y Millar (1991), Microeconomía, México., Mac Graw Hill.

Marx, Karl (1980) (a), El Capital. Crítica de la Economía Política, El proceso de producción del capital (Libro Primero, Vol. 1, 2 y 3). México, Siglo xxi.

Marx, Karl (1982), El Capital. Crítica de la Economía Política. El proceso de circulación del capital (Libro Segundo, Vol. 4 y 5), México Siglo xxi.

Marx, Karl (1984), El Capital. Crítica de la Economía Política. El proceso global de la producción capitalista (Libro Tercero, vol. 6.7 y 8), México, Siglo xxI.

Marx, Karl (1976), Elementos fundamentales para la crítica de la economía política (gudrisse) 1857-1858, Tomo 2, México, Siglo xxi.

Miriam Núñez Torrado (2000), Santander Revista de Contabilidad Vol 3, n 6 juliodiciembre 2000 p. 135-143.

Montes Salazar C A, et al., 2006, Paradigmas de la contabilidad. Cali GICIC-GIProcof

Walter Carrizo Silvia León, 2007, ¿Qué realidad representa la contabilidad? Rivadavia Provincia de Chubut (Argentina), Pecvnia, 5 (2007), pp. 17-27. 